US Army Corps

of Engineers ${ }_{\circledast}$

Engineer Research and

Development Center

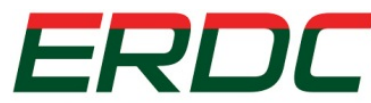

INNOVATIVE SOLUTIONS

for a safer, better world

Department of Defense Corrosion Prevention and Control Program

Polymer Composite Wrapping and Cathodic Protection System for Reinforced Concrete Piles in Marine Applications

Final Report on Project F08-AR07

David M. Bailey, Vincent F. Hock, P.A. Noyce, and M. Restly

June 2013

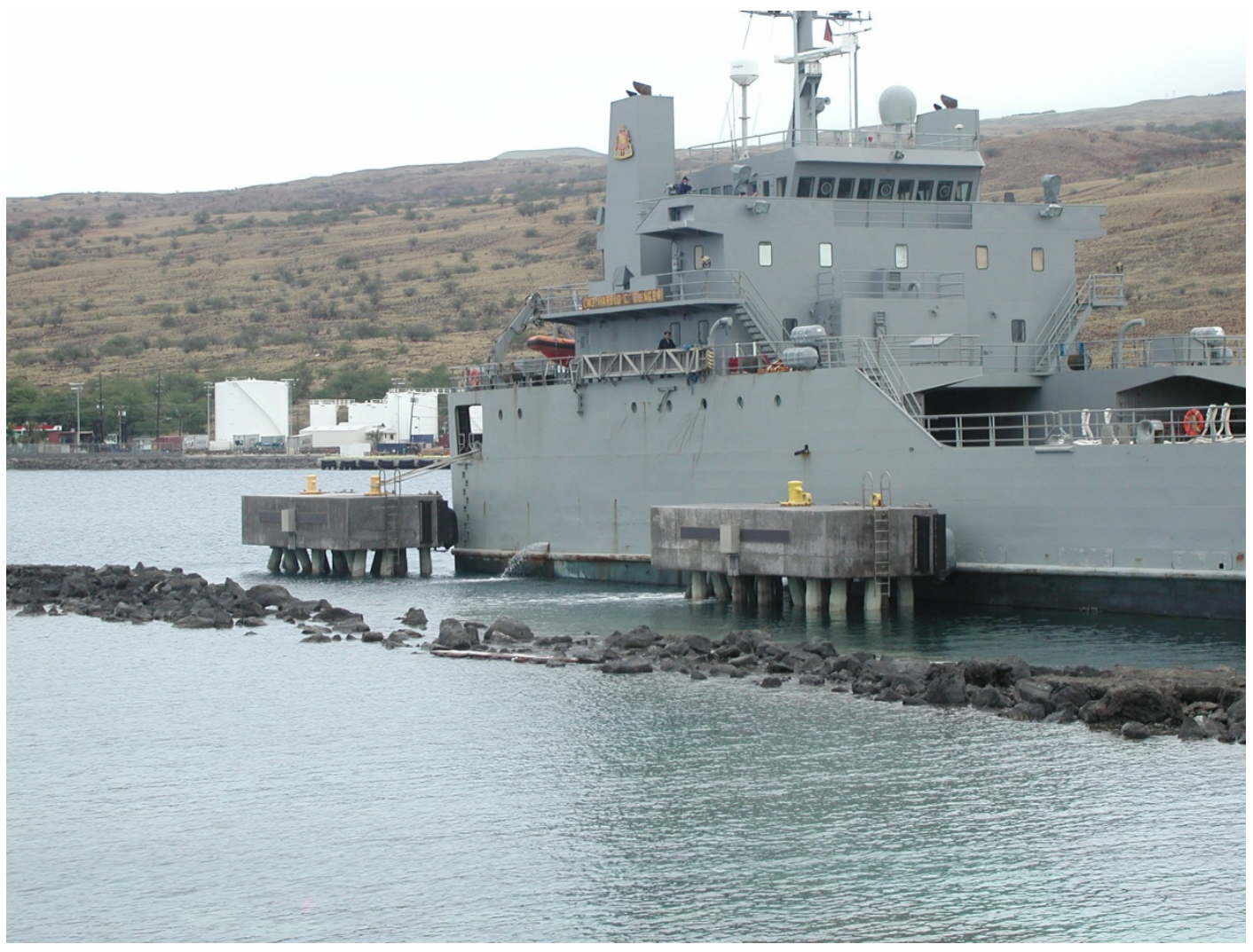


The US Army Engineer Research and Development Center (ERDC) solves the nation's toughest engineering and environmental challenges. ERDC develops innovative solutions in civil and military engineering, geospatial sciences, water resources, and environmental sciences for the Army, the Department of Defense, civilian agencies, and our nation's public good. Find out more at www.erdc.usace.army.mil.

To search for other technical reports published by ERDC, visit the ERDC online library at http://acwc.sdp.sirsi.net/client/default. 


\section{Polymer Composite Wrapping and Cathodic Protection System for Reinforced Concrete Piles in Marine Applications}

Final Report on Project F08-AR07

David M. Bailey and Vincent F. Hock

Construction Engineering Research Laboratory

US Army Engineer Research and Development Center

2902 Newmark Drive

Champaign, IL 61822

P. A. Noyce and M. Restly

Electro Tech CP, LLC

354 Cypress Drive, Suite 10

Tequesta, FL 33469

Final report

Approved for public release; distribution is unlimited.

Prepared for Office of the Secretary of Defense (OUSD(AT\&L))

3090 Defense Pentagon

Washington, DC 20301-3090

Under Project F08-AR07, “Polymer Composite Wrapping and Ceramic Anode Cathodic Protection System for Pilings at Kawaihae Harbor, $\mathrm{HI}$ 


\section{Abstract}

Military piers in marine environments are typically supported atop steelreinforced concrete piles that are subject to corrosion and concrete deterioration. The failure of even one pile presents a risk of catastrophic structural failure and interruption of operations. Patching deteriorated concrete does not stop corrosion of the reinforcement and may even accelerate it. An impact and corrosion protection wrap (ICPW) system, incorporating a composite structural wrap and cathodic protection system, was designed to rehabilitate deteriorated steel-reinforced concrete marine piles in service at Kawaihae Harbor, HI. The purpose of the technology is to reduce pier life-cycle costs and downtime by inhibiting corrosion-related damage to steel-reinforced concrete piles.

The ICPW system consists of a composite reinforced polymeric wrap with an integrated galvanic anode to provide protection in the tidal splash zone. Corrosion activity in 20 rehabilitated piles on two piers was monitored using reference electrodes and data loggers. Results of the demonstration indicate that the system can protect and extend the life of in-service reinforced concrete structural piles in a corrosive marine environment. An economic analysis determined that full implementation of the system on all piles of the two demonstration piers would provide 3.16 return on investment.

DISCLAIMER: The contents of this report are not to be used for advertising, publication, or promotional purposes. Citation of trade names does not constitute an official endorsement or approval of the use of such commercial products. All product names and trademarks cited are the property of their respective owners. The findings of this report are not to be construed as an official Department of the Army position unless so designated by other authorized documents. 


\section{Contents}

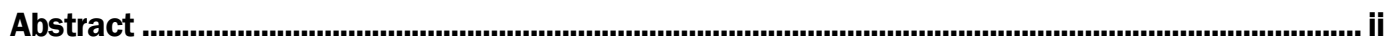

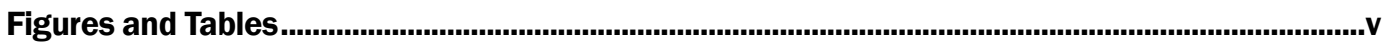

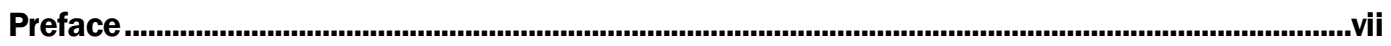

Executive Summary .................................................................................................................... vii

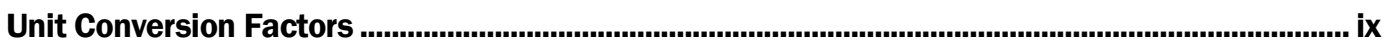

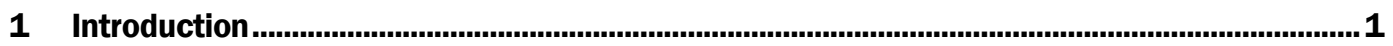

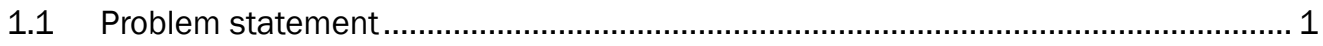

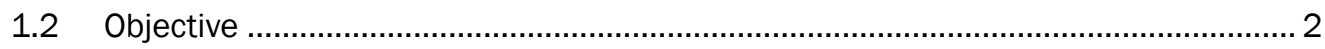

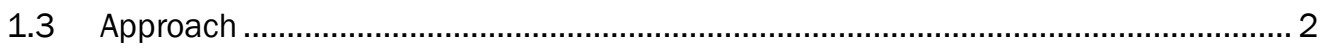

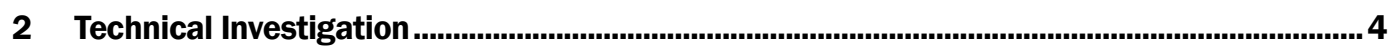

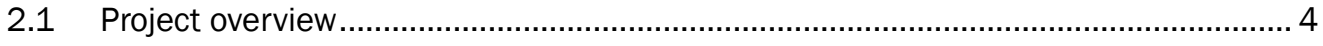

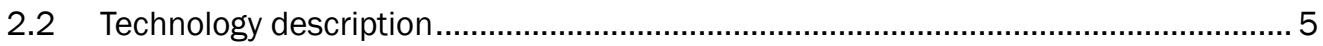

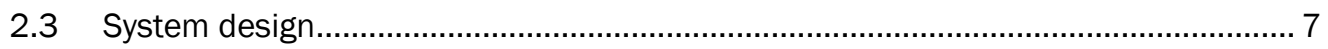

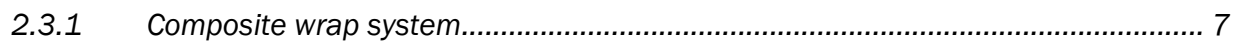

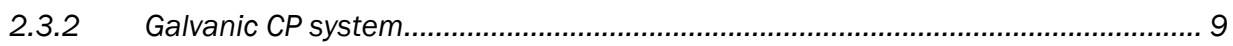

2.3.3 Corrosion monitoring system....................................................................... 12

2.3.4 Electrical equipment............................................................................. 14

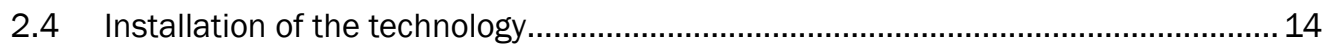

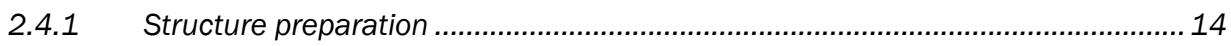

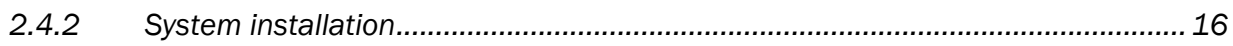

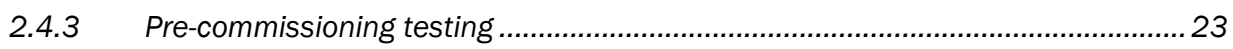

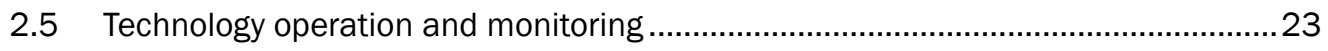

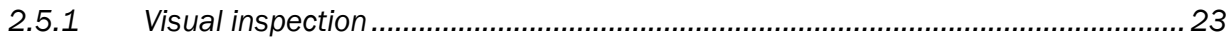

2.5.2 Initial energizing and adjustments............................................................... 23

2.5.3 Initial performance testing and verification .................................................... 24

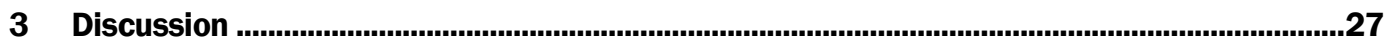

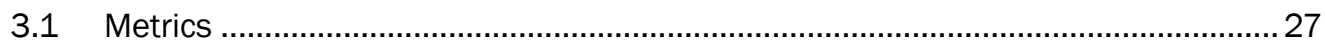

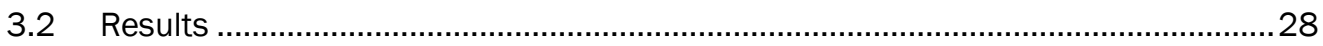

3.2.1 Dolphin 2 - monitored piles having full ICPW system ........................................ 28

3.2.2 Dolphin 2 - monitored control piles .................................................................... 32

3.2.3 Dolphin 3 - monitored piles having full ICPW system .......................................... 34

3.2.4 Dolphin 3 - monitored control piles ............................................................... 37

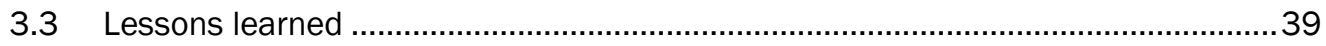

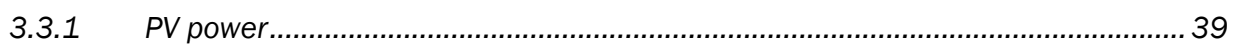

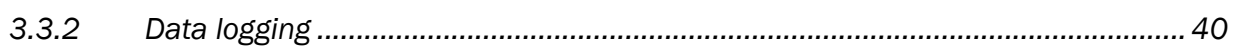

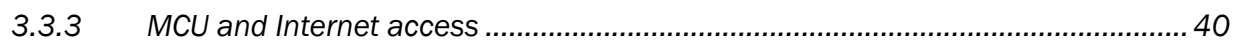




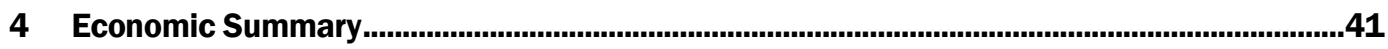

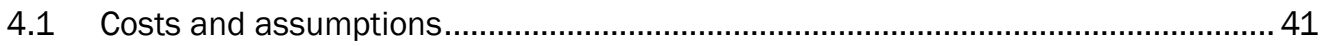

4.2 Projected return on investment (ROI) ........................................................... 42

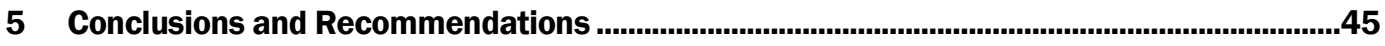

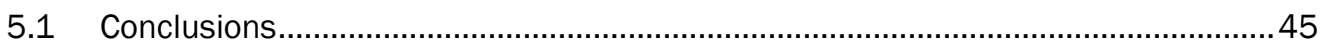

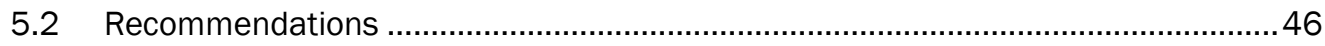

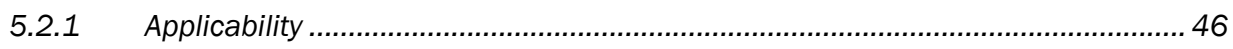

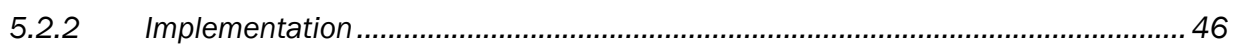

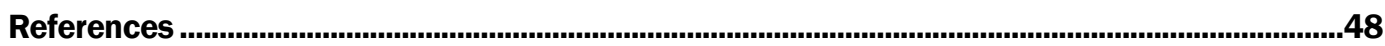

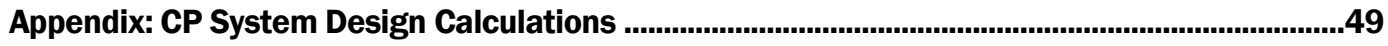

Report Documentation Page 


\section{Figures and Tables}

\section{Figures}

Figure 1. Cracking and spalling of concrete pile due to steel corrosion............................................. 1

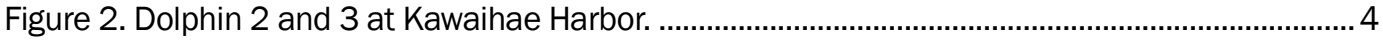

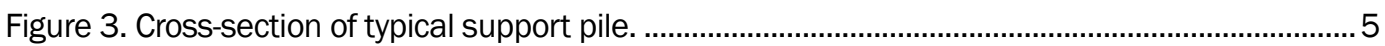

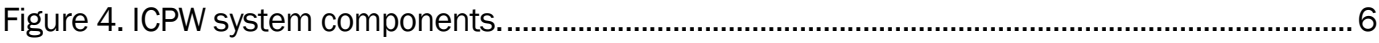

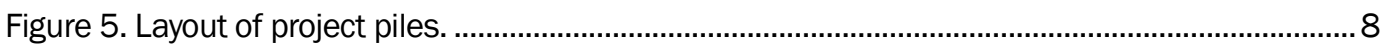

Figure 6. Assembled apron of eight mesh anode strips.......................................................................15

Figure 7. Floating raft used to transport materials and crew. ............................................................16

Figure 8. Bulk anode installed at -8.0 MSL elevation. ...................................................................17

Figure 9. Plugs removed and steel rod placed in grooves.............................................................18

Figure 10. Anode assembly positioned against pile..........................................................................20

Figure 11. Diver placing compression panel over anode assembly ..................................................20

Figure 12. Finished composite wrap assembly..............................................................................21

Figure 13. RMU and PV panel mounted on west face of dolphin pier. .............................................22

Figure 14. Junction box and conduit attached to underside of pier................................................22

Figure 15. Instant-off potentials for first year, Dolphin 2, Pile 1 (full system)....................................29

Figure 16. Output current for first year, Dolphin 2, Pile 1 (full system) .............................................30

Figure 17. Instant-off potentials for first year, Dolphin 2, Pile 3 (full system).....................................30

Figure 18. Output current for first year, Dolphin 2, Pile 3 (full system).............................................30

Figure 19. Instant-off potentials for first year, Dolphin 2, Pile 11 (full system). .................................31

Figure 20. Output current for first year, Dolphin 2, Pile 11 (full system)............................................31

Figure 21. Instant-off potentials for first year, Dolphin 2, Pile 21 (full system)...................................31

Figure 22. Output current for first year, Dolphin 2, Pile 21 (full system)...........................................32

Figure 23. Instant-off potentials for first year, Dolphin 2, Pile 17 (wrap and bulk CP)........................33

Figure 24. Instant-off potentials for first year, Dolphin 2, Pile 13 (wrap and no CP)..........................33

Figure 25. Instant-off potentials over first year, Dolphin 2, Pile 15 (no wrap or CP)...........................34

Figure 26. Instant-off potentials for first year, Dolphin 3, Pile 2 (full system)....................................35

Figure 27. Output current for first year, Dolphin 3, Pile 2 (full system) .............................................35

Figure 28. Instant-off potentials for first year, Dolphin 3, Pile 4 (full system) .....................................35

Figure 29. Output current for first year, Dolphin 3, Pile 4 (full system). ............................................36

Figure 30. Instant-off potentials for first year, Dolphin 3, Pile 12 (full system). ................................36

Figure 31. Output current for first year, Dolphin 3, Pile 12 (full system). ...........................................36

Figure 32. Instant-off potentials for first year, Dolphin 3, Pile 8 (full system)......................................37

Figure 33. Output current for first year, Dolphin 3, Pile 8 (full system). .............................................37

Figure 34 Instant-off potentials for first year, Dolphin 3, Pile 17 (wrap and bulk CP)........................38 
Figure 35. Instant-off potentials for first year, Dolphin 3, Pile 14 (wrap only).....................................38

Figure 36. Instant-off potentials for first year, Dolphin 3, Pile 16 (no wrap or CP).............................39

\section{Tables}

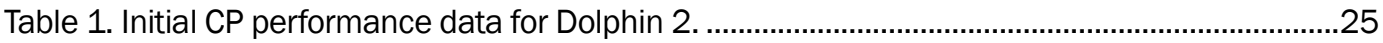

Table 2. Initial CP performance data for Dolphin 3. ……..............................................................26

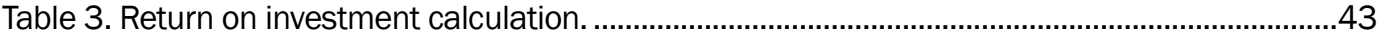

Table 4. Yearly costs and benefits for baseline and new technology scenarios..................................44 


\section{Preface}

This demonstration was performed for the Office of the Secretary of Defense (OSD) under Department of Defense (DoD) Corrosion Prevention and Control Project F08-AR07, "Polymer Composite Wrapping and Ceramic Anode Cathodic Protection System for Pilings at Kawaihae Harbor, HI." The proponent was the US Army Office of the Assistant Chief of Staff for Installation Management (ACSIM), and the stakeholder was the US Army Installation Management Command (IMCOM). The technical monitors were Daniel J . Dunmire (OUSD(AT\&L)), Bernie Rodriguez (IMPWFM), and Valerie D. Hines (DAIM-ODF).

The work was performed by the Engineering and Materials Branch (CEERD-CF-M), Facilities Division (CF), US Army Engineer Research and Development Center, Construction Engineering Research Laboratory (ERDC-CERL), Champaign, IL. The ERDC-CERL project manager was Mr. David M. Bailey. The ERDC CPC Program Manager was Michael K. McInerney, CEERD-CF-M. At the time this report was prepared, the Chief of the ERDC-CERL Materials and Structures Branch was Vicki L. Van Blaricum (CEERD-CF-M), the Chief of the Facilities Division was L. Michael Golish (CEERD-CF), and the Technical Director for Installations was Martin J . Savoie (CEERD-CV-ZT). The Deputy Director of ERDC-CERL was Dr. Kirankumar Topudurti and the Director was Dr. Ilker Adiguzel.

The following PTA personnel are gratefully acknowledged for their support and assistance in this project:

Mr. Eugene Arther - Facility Manager Supervisor, Directorate of Public Works (DPW), Wheeler AAF, HI

- Matt Miltenberger, Tourney Consulting, Inc. Kalamazoo, MI

- Thomas Tehada, Naval Facilities Engineering Service Center, Pearl Harbor, HI.

COL Kevin J. Wilson was the Commander of ERDC, and Dr. J effery P. Holland was the Director. 


\section{Executive Summary}

Military wharves and piers in marine environments are typically supported atop steel-reinforced concrete piles that are subject to corrosion and concrete deterioration. The failure of even one pile presents a risk of catastrophic failure and interruption of operations. Patching deteriorated concrete does not stop corrosion of the reinforcement, and sometimes accelerates it, because exposure of the steel to chlorides, moisture, and oxygen continues. The cost to replace an entire structure is very high. Even where funds for replacement are available, demolition and reconstruction activities will interfere with mission execution and safety.

An impact and corrosion protection wrap (ICPW) system was demonstrated on two deteriorated dolphin piers at Kawaihae Harbor, HI. It consisted of a composite reinforced polymeric wrapping with integrated galvanic cathodic protection (CP). A corrosion monitor, data logging capability, and high-speed Internet connection were installed to document system performance. The ICPW was designed to (1) structurally reinforce the concrete piles, (2) protect the piles from impact and abrasion damage, (3) be applied underwater, (4) inhibit corrosion of the reinforcing steel, and (5) require little or no maintenance. NACE Standard Practice SP0169-2007, "Control of External Corrosion on Underground or Submerged Metallic Piping," was the metric for steel immunity to corrosion. All system components are commercially available. The ICPW system was installed by a dive crew and a CP installation crew on 10 piles supporting each of two piers. For control purposes, the ICPW system was not applied to some piles, and some demonstration piles were given different levels of $\mathrm{CP}$.

This report documents results of the demonstration, which indicate that the system can protect and extend the life of in-service reinforced concrete structural piles in a corrosive marine environment. Monitoring of the control piles with no CP during the demonstration period shows corrosion proceeding at a rate that would lead to failure and necessary replacement within 15 years. Lessons learned are documented, including issues related to location of the system's photovoltaic power panels and to installing ICPW system control software on computers with Department of Defense security settings. Full implementation of the ICPW system on the two demonstration piers at Kawaihae Harbor would provide an ROI of 4.44. 


\section{Unit Conversion Factors}

\begin{tabular}{|l|c|l|}
\hline Multiply & By & To Obtain \\
\hline degrees Fahrenheit & $(\mathrm{F}-32) / 1.8$ & degrees Celsius \\
\hline feet & 0.3048 & meters \\
\hline gallons (US liquid) & $3.785412 \mathrm{E}-03$ & cubic meters \\
\hline in. & 0.0254 & meters \\
\hline mils & 0.0254 & millimeters \\
\hline square feet & 0.09290304 & square meters \\
\hline
\end{tabular}




\section{Introduction}

\subsection{Problem statement}

Department of Defense (DoD) piers and wharves, most of which are over 50 years old, have a combined annual cost of corrosion of $\$ 14.5 \mathrm{M}$ and a total annual maintenance cost of \$99M (LMI 2007). These marine structures are often supported using steel-reinforced concrete piles. The piles are exposed to a marine environment that can severely corrode reinforcement steel and spall the concrete (Figure 1). Because every pile in a pier is necessary for structural stability, the failure of even one can have a catastrophic effect on the structure and disrupt operations of the port. If these structures are taken out of service because of a corrosion-induced failure of support piles, they could have serious negative impact on DoD readiness or mission. The costs to replace entire structures is very high. Even if funds are available for replacement, demolition and reconstruction will interfere with mission execution and safety.

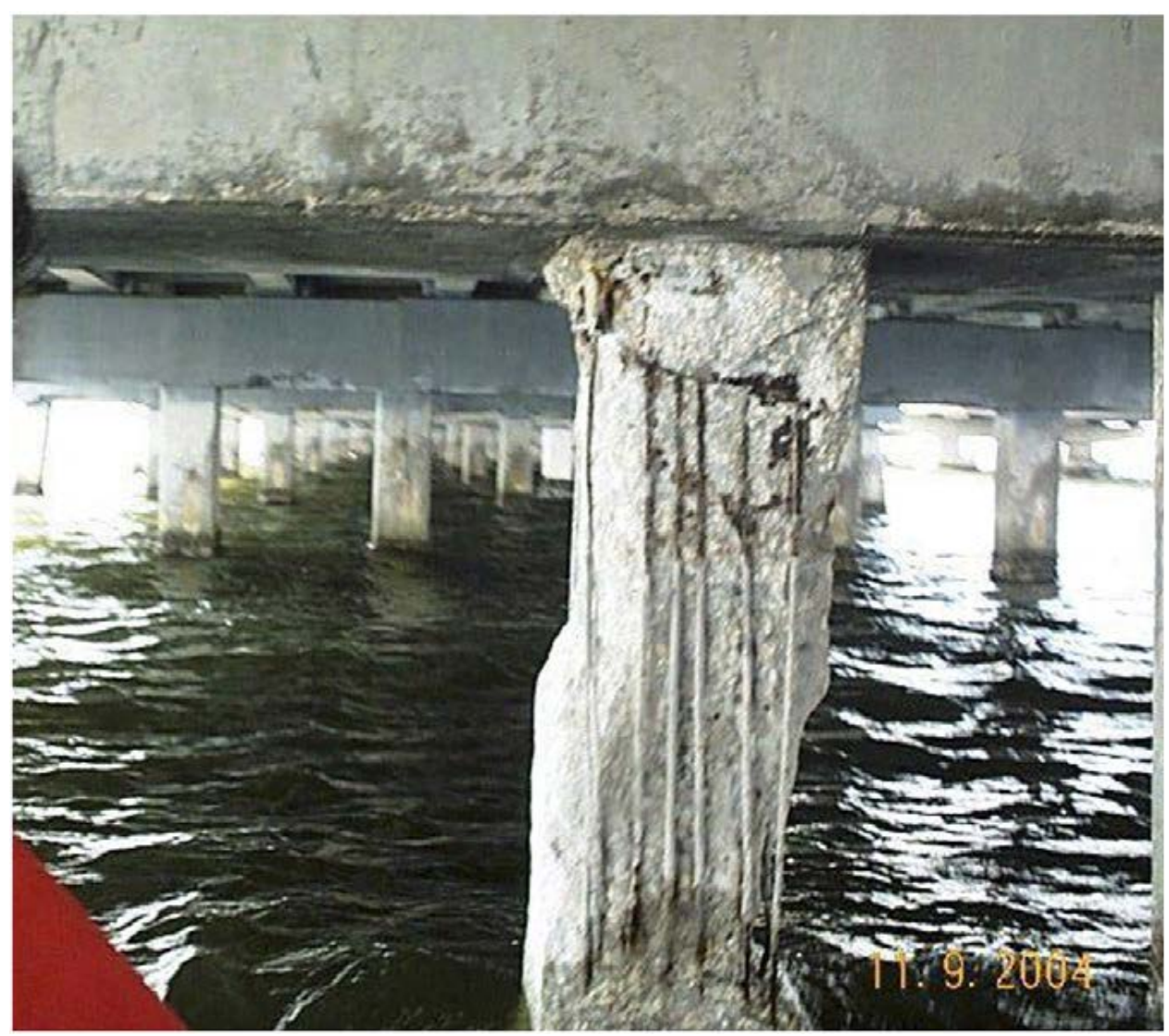

Figure 1. Cracking and spalling of concrete pile due to steel corrosion. 
For marine piles, simple patching of the deteriorated concrete is usually only a temporary solution because it does not stop corrosion of the reinforcement caused by the continued presence of chlorides, moisture, and oxygen from the seawater. In fact, corrosion rates may be accelerated in the vicinity of new patches.

Fiber-reinforced polymer (FRP) composite wrapping systems have been evolving over the last 20 years and are now a viable solution for structural repair to physically damaged piles in marine environments (Sen 2007, Verhulst 2001). However, use of these systems for repairing corrosion damage has not been completely successful. The composite wraps may contain the concrete but do not arrest corrosion of the reinforcing steel. Some systems, such as the LifeJ acket ${ }^{\circledR}$ pile system demonstrated by the Navy under FY05 Corrosion Prevention and Control (CPC) Project N-F2294, attempt to address this issue by incorporating sacrificial anodes under a prefabricated rigid composite shell (Tehada 2008). These systems have limitations both in their structural capabilities their usefulness on piles of certain sizes and shapes.

A cost-effective technology is needed to provide corrosion and impact resistance to deteriorated steel-reinforced concrete marine piles to significantly reduce corrosion problems. A system composed of a tough, composite reinforced polymeric wrapping that incorporates galvanic cathodic protection could provide these necessary properties. Another special requirement is that such as system could be applied underwater where dewatering would be cost-prohibitive.

\subsection{Objective}

The objective of this project was to develop and demonstrate a protective pile composite wrapping system that (1) structurally reinforces the concrete piles, (2) provides protection from impact and abrasion damage, (3) can be applied underwater, (4) inhibits corrosion of the reinforcing steel, and (5) requires little or no maintenance.

\subsection{Approach}

The pile-wrapping system to be demonstrated was designed, fabricated, and installed to repair and protect the support piles under two dolphin piers (or "dolphins") at Kawaihae Harbor, HI. 
As part of a contract with the US Army Engineer Research and Development Center, Construction Engineering Research Laboratory (ERDCCERL), ElectroTech CP, LLC, was contracted by Mandaree Enterprise Corporation (MEC) to develop an impact and corrosion protection wrap (ICPW) system that incorporates both mechanical protection of the exterior surfaces of marine concrete piles and corrosion protection of their steel reinforcement. After approval of the design, the contractor fabricated and assembled the system components and installed it on selected piles, collected corrosion potential data for 1 year, and performed scheduled inspections.

The integrated cathodic protection (CP) system was designed in accordance with the following standards:

- NACE SP0290-2007, "Cathodic Protection of Steel in Atmospherically Exposed Concrete Structures"

- NACE RP0187-2005, "Design Considerations For Corrosion Control of Reinforcing Steel in Concrete"

- NACE SP0169-2007, "Control of External Corrosion on Underground or Submerged Metallic Piping." 1

The materials and components incorporated into the design were compliant with applicable standards and criteria specified in the following sources:

- National Electrical Code (NEC)

- American Society for Testing and Materials (ASTM)

- National Electrical Manufactures Association (NEMA)

- American National Standards Institute (ANSI). 


\section{Technical Investigation}

\subsection{Project overview}

The demonstration site, Kawaihae Harbor, is located on the northwest part of the big island of Hawaii and is home to a commercial port facility. Within the harbor, there is a watercraft docking facility used for shipments to and from the US Army Pohakuloa Training Area (PTA), which is located further inland. The dock has three concrete mooring dolphin piers and an adjacent concrete ramp on the adjacent shore. The dolphin piers are in alignment from north to south and numbered from 1 to 3, with Dolphin 3 being farthest from the shore. Dolphin 1, which is older than the other two and of different construction, is scheduled for demolition and was not included in the project.

Dolphins 2 and 3 were built in 2000. They are reinforced concrete platform/ pile cap structures measuring approximately $34 \mathrm{ft} \mathrm{long} \mathrm{by} 14 \mathrm{ft}$ wide by $6.5 \mathrm{ft}$ deep. The bottom of the pile cap elevation for each is approximately $4 \mathrm{ft}$ above mean seal level (+4.0 ft MSL). The structures (Figure 2) are supported by gangs of prestressed concrete piles driven directly into the bottom of the harbor sea floor. Dolphin 2 has 21 piles and Dolphin 3 has 19 piles.

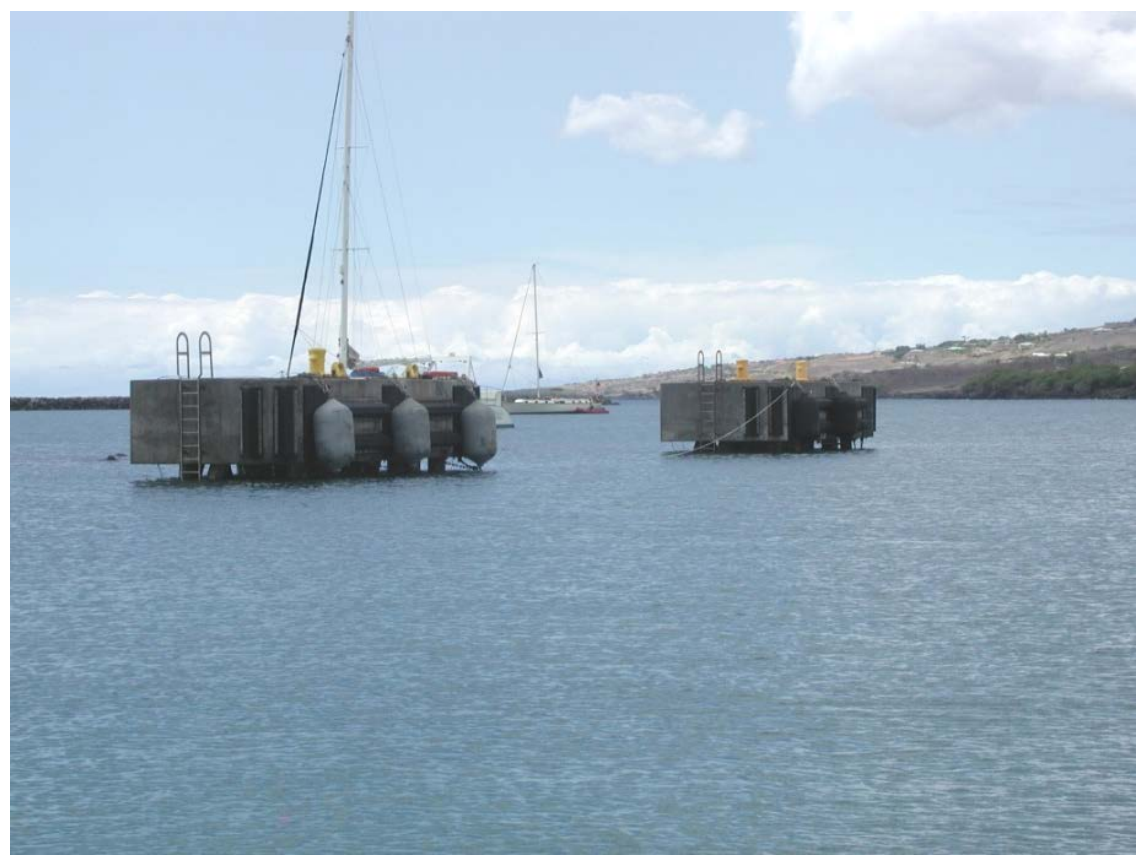

Figure 2. Dolphin 2 and 3 at Kawaihae Harbor. 
The piles are about $70 \mathrm{ft}$ long and have octagonal cross-sections with 7.5 in. faces (Figure 3). They are in relatively good condition, with indications of only very minor damage within the splash zone region. The chloride ion contamination profile extracted from one of the piles indicates chloride contamination has penetrated beyond a depth of $2 \mathrm{in}$. into the concrete, but has not yet reached the prestressing tendons.

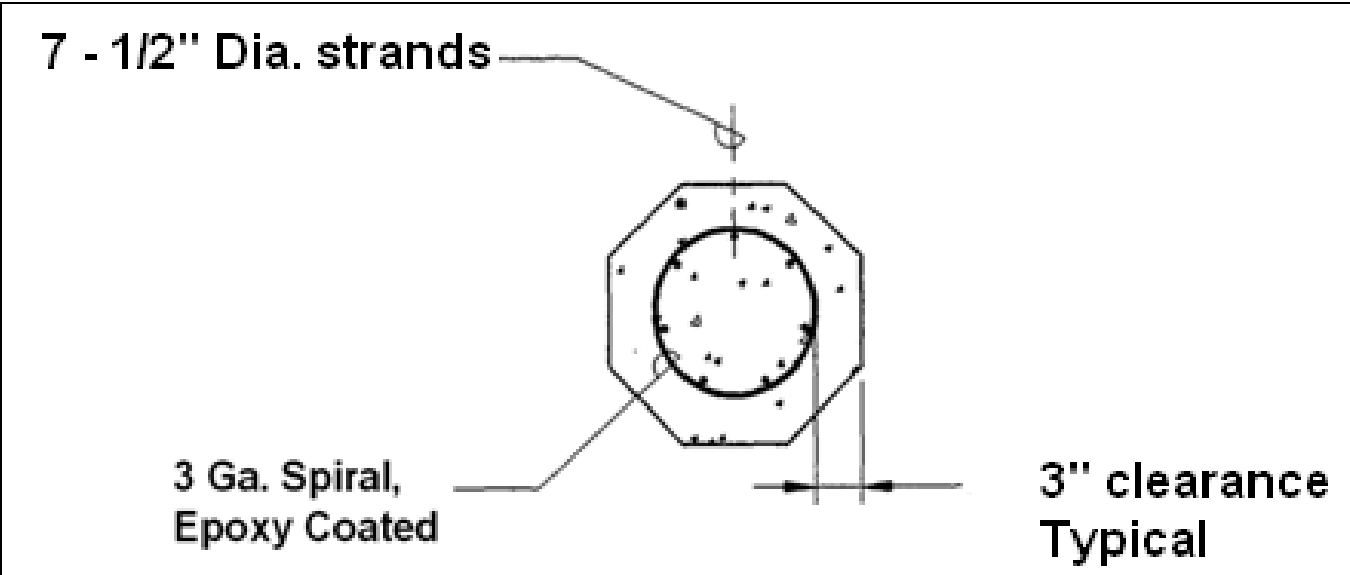

\section{Octagonal 7-1/2" face}

Figure 3. Cross-section of typical support pile.

The contractor was directed to design and develop a thermoset FRP pile wrapping system utilizing commercially available products. Contract requirements stated that the wrapping system was to be designed for underwater installation and intended for use in protecting piles in the splash zone region from impact damage caused by floating debris. For this project the splash zone was defined as the $8 \mathrm{ft}$ length of pile that starts at approximately $18 \mathrm{in}$. below the bottom surface of the concrete platform $(+2.5 \mathrm{ft}$ MSL) and extends downward to elevation $-5.5 \mathrm{ft}$ MSL. The system was also to be integrated with a galvanic CP system that would protect the reinforcing steel in the wrapped portion of the pile. Additional CP was required for the submerged portion of the pile that was not to be wrapped. To monitor its effectiveness, a corrosion-monitoring system utilizing the half cell potential method was to be installed on selected piles.

\subsection{Technology description}

The contractor's proposed design (Figure 4) integrates three technologies: FRP composite wrap, galvanic $\mathrm{CP}$, and corrosion monitoring. 
The composite wrap system encapsulates the pile in the splash zone and provides protection against abrasion and mechanical damage to the pile surface and the $\mathrm{CP}$ anode assembly underneath it. The wrap material is a woven glass fiber pre-impregnated with moisture-activated resins that cure underwater after being put in place.

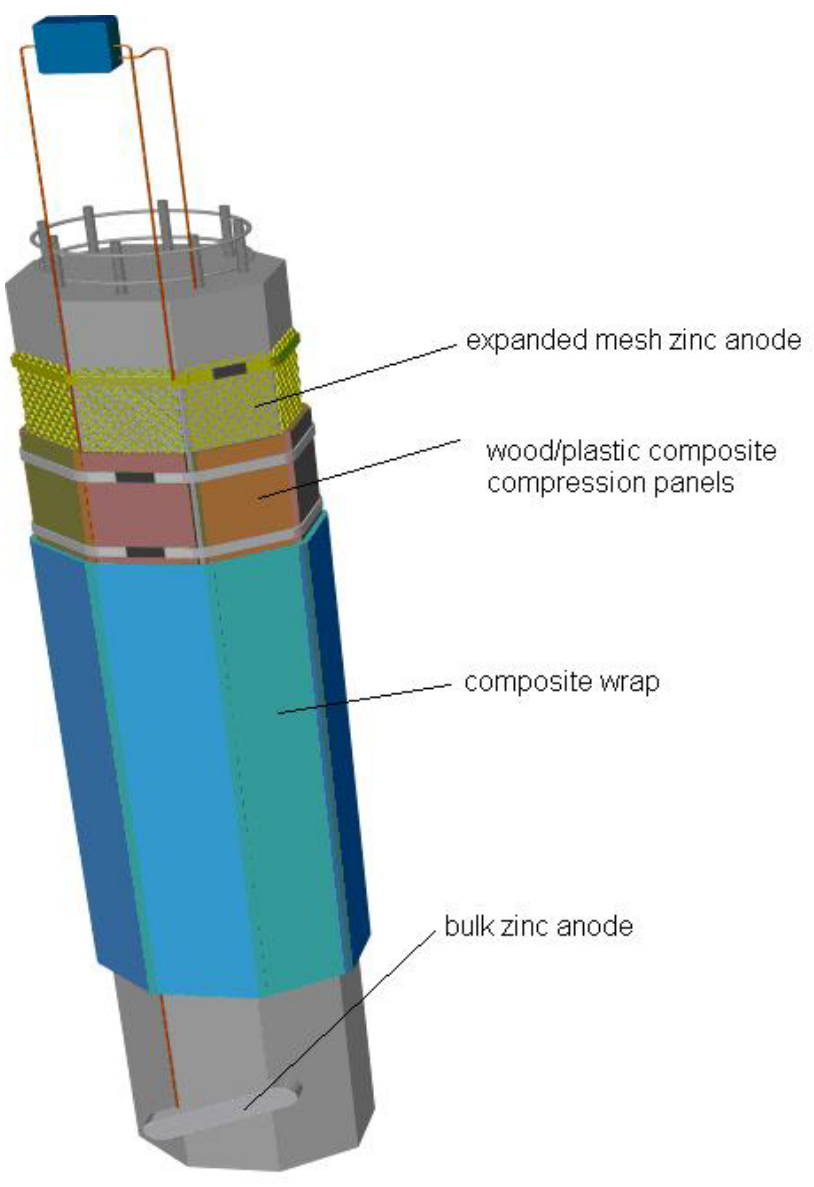

Figure 4. ICPW system components.

The CP anode assembly that protects the wrapped section of pile is composed of expanded mesh strips and compression panels. The mesh strips, made of high-purity zinc, are placed against each face of the octagonal pile. They function as sacrificial anodes to protect the reinforcement steel in the wrapped portion of the pile. The strips are held against the pile surfaces by wood composite compression panels that are banded in place. A bulk zinc anode supplements the integrated CP system and provides protection for the reinforcement steel in the unwrapped portion of the pile. 
The CP performance of the ICPW system is verified by installing a monitoring and control system on selected piles of each of the two dolphins. Reference electrodes are distributed along the piles and provide a means of determining the polarization level of the steel with time. A remotemonitoring system was designed to collect performance data from each of the monitored piles on both dolphins and provide access through the Internet.

\subsection{System design}

Funding was available to include 10 piles on each pier for both the composite wrap and the full CP system. Three additional piles were selected to serve as controls: one received the composite wrap with CP for the unwrapped portion of the pile only; the second received only the composite wrap and no CP; and the third had neither composite wrap nor CP. For both piers, all three control piles and four of the fully treated piles were instrumented with the corrosion monitoring system. Figure 5 shows the layout of the project piles.

The design life of the ICPW is 20 years, and is dictated by the expected service life of its individual components:

- FRP composite wrap material-20 years

- silver/ silver chloride reference electrodes-20 years

- anode system-20 years

- monitoring system and electrical installation-20 years.

\subsubsection{Composite wrap system}

The FRP composite wrap material that was selected is Aqua Wrap Type G05, a woven glass fiber pre-impregnated with moisture-activated resins. The uncured material is shipped in sealed bags to protect it from atmospheric moisture. Once removed from the protective bag, the resins begin to cure through a chemical reaction with field-applied water. It has a working time of 60 minutes in air, depending on ambient humidity, and a nominal cure time of 30 minutes underwater. 


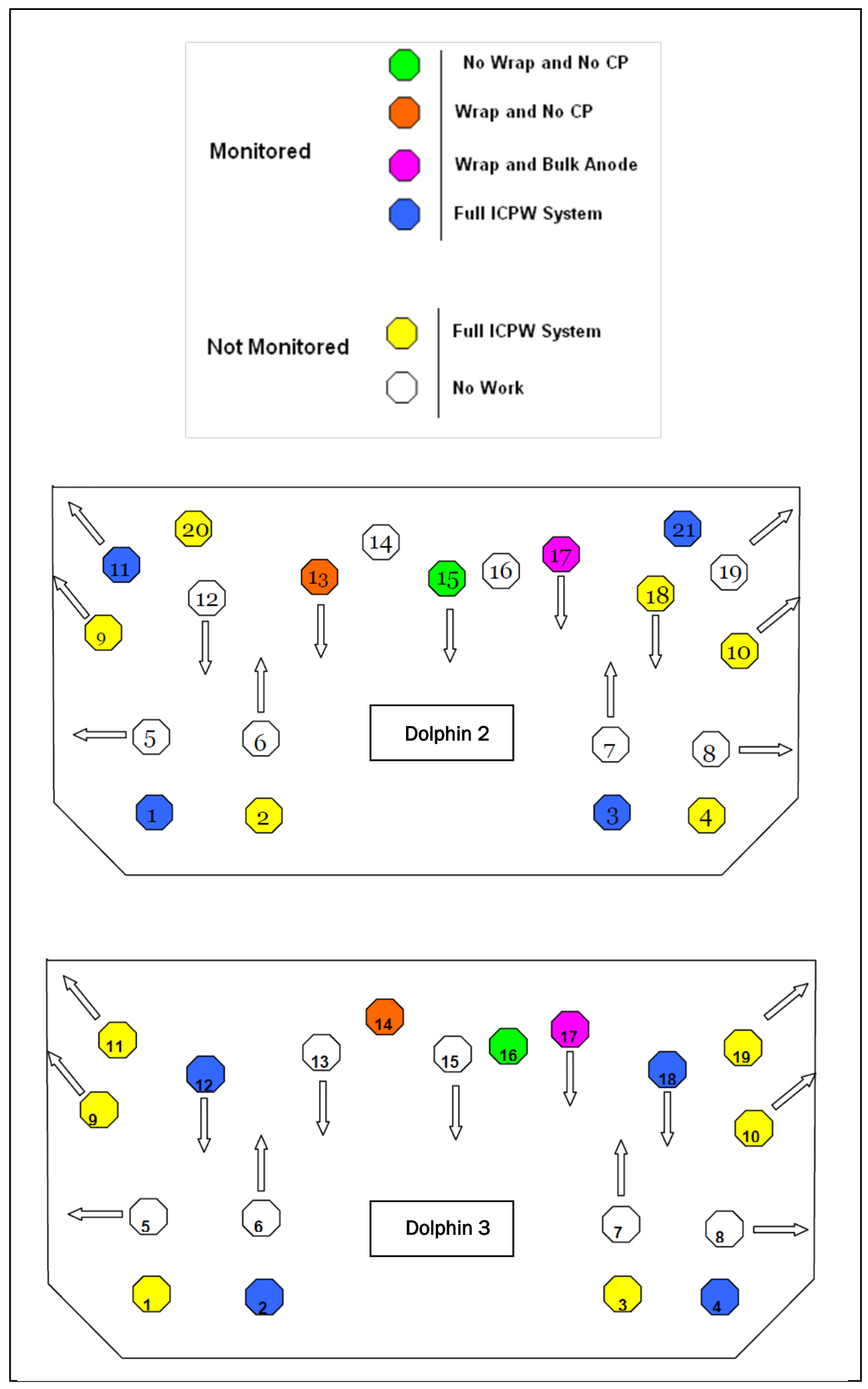

Figure 5. Layout of project piles. 
The manufacturer's data sheets specify the following general characteristics and mechanical properties of the wrap:

- General Characteristics

o Tg. $-288^{\circ} \mathrm{F}$

o chemical resistance - resistant to acetone, MEK, toluene, gasoline, ethyl alcohol

o adhesion - 1,000 psi (lap shear) to abraded carbon steel, using Air Log BP-1 primer; 500 psi to concrete per ASTM D4541.

- Mechanical Properties

o reinforcement - woven glass bi-axial fabric

o dry fabric weight (oz./ sq yd) - 24

o nominal thickness (mils) - 27

o tensile strength (psi) - 47,500

o tensile modulus (e-6psi) - 3.2

o tensile load, per ply (pounds) - 1,280

o compressive strength (psi) - 25,000

o interlaminar shear (psi) - 2,750.

\subsubsection{Galvanic CP system}

\subsubsection{Anodes}

The design calculations for the CP system are provided in the Appendix. Protection from the CP system is determined by the open circuit potential. The level of current needed to provide corrosion protection is referred to as the current density. The steel current density is not treated as a fixed parameter for the design of the CP system. In saturated, low-oxygen environments such as those found in partially submerged concrete piles, steel current demand can be reduced to negligible levels after cathodic polarization. This is because the lack of oxygen prevents significant depolarization at the cathodic sites. Thus, current density is expected to vary from a maximum level before polarization to very low levels after activation of the $\mathrm{CP}$ system. For anode output calculation purposes, the designers used a steel current density range of $0.1 \mathrm{~mA} / \mathrm{sq} \mathrm{ft}$ to $1.0 \mathrm{~mA} / \mathrm{sq} \mathrm{ft}$.

The anode system has a design working life of 20 years. It is constructed of expanded zinc mesh and bulk zinc. These anodes are expected to exceed the design life as consumption is mainly dictated by the galvanic current output, and the demand will be low. This is a demonstration project, and as such, the intent is to confirm that the anode system will be capable of 
meeting protection criteria as established in NACE SP0290-2007, "Cathodic Protection of Steel in Atmospherically Exposed Concrete Structures." The design of the anode system attempts to meet or exceed these criteria.

The zinc mesh used for the design conforms to A-190 expanded sheet (certified to ASTM B69-09), with the following composition:

- $\mathrm{Pb}-0.005 \%$ wt. max.

- $\mathrm{Fe}-0.001 \%$ wt. max.

- $\mathrm{Cd}-0.005 \%$ wt. max.

- $\mathrm{Cu}-0.7-0.9 \%$ wt. max.

- $\mathrm{Al}-0.001 \%$ wt. max.

- Zn-balance.

Based on the manufacturer's data, the mesh has the following physical properties and geometry:

- Physical properties

o electrical conductivity $=28 \%$ IACS

o Solid zinc density $=0.259 \mathrm{psi}$

0 weight of expanded mesh $=1.60 \mathrm{lb} / \mathrm{sq} \mathrm{ft}$

o open area of expanded mesh $=53 \%$ (density)

o solid zinc sheet thickness $=0.90$ in.

- Geometry

o 0.5 in. hex pattern

o $\quad 0.125 \mathrm{in}$. strand width in short direction

o 0.520 in. strand width in long direction

o 0.320 in. short opening

o 0.780 in. long opening.

The zinc mesh sheets are fabricated to 7x 96 in. dimensions.

For each of the project piles, a $48 \mathrm{lb}$ (51 lb gross) bulk zinc anode is used to provide CP for the reinforcement steel in the unwrapped and submerged portion. These anodes conform to ASTM B-418 for a Type I anode and are 99\% pure zinc with a steel strap core. The steel strap is hot-dip galvanized with a minimum zinc thickness of 0.005 in. A 3/4 in. diameter hole was predrilled at each end of the steel strap prior to galvanizing. 


\subsubsection{Compression panels}

For each face of the pile, a compression panel was used to secure the zinc sheet to the concrete surface. The panels are fabricated from a wood/ plastic composite material. The dimension of each panel is $0.75 \mathrm{in} . \mathrm{x}$ $6.50 \mathrm{in} . \mathrm{x} 8.00 \mathrm{ft}$. The contact face of each panel was cut with $0.25 \mathrm{in}$. longitudinal grooves to allow for wicking action of sea water between the panel and pile surface.

The compression panels have the following physical and mechanical properties (extracted from manufacturer's data sheet):

- abrasion resistance $=0.01$ wear/ 1000 revs per ASTM D2394

- hardness =1,124 lb per ASTM D143

- water absorption (sanded surface, $24 \mathrm{hrs}$ ) $=4.3 \%$ per ASTM D 1037

- water absorption (unsanded surface, $24 \mathrm{hrs}$ ) $=1.7 \%$ per ASTM D1037

- specific gravity (typical) $=0.91$ to 0.95 per ASTM D2395

- compression parallel =1,806 psi per ASTM D198

- compression perpendicular =1,944 psi per ASTM D143

- tensile strength $=854$ psi per ASTM D198

- shear strength =561 psi per ASTM D143

- modulus of rupture =1,423 psi per ASTM D4761

- modulus of elasticity =175,000 psi per ASTM D4761

- thermal conductivity $=1.57 \mathrm{BTU}$-in $/ \mathrm{hr}$-ft at $85^{\circ} \mathrm{F}$ per ASTM C177.

Stainless steel banding at $1 \mathrm{ft}$ intervals was specified to secure the panels in place.

\subsubsection{Cathodic protection direct current (DC) cables}

All single core field cables used for the anodes and reference electrodes were 14 American wire gauge (AWG) stranded copper with high molecular weight polyethylene (HMWPE) insulation or MiL-W-16878-4 Teflon.

\subsubsection{Repair mortar}

A non-shrink Portland cement concrete repair mortar was specified to fill concrete excavations made to establish electrical continuity between steel tendons within the piles and to facilitate any necessary repairs performed within the wrapped section. The rapid-setting mortar was extended with 
basalt aggregate, providing a resistivity similar to that of the pile concrete. The mortar was required to have the following properties:

- electrical resistivity less than 50,000 ohm-cm (at 28 days)

- electrochemically resistant to anode reaction products

- workability properties appropriate for the method of placement

- no cracking due to thermal and/ or shrinkage effects.

\subsubsection{Corrosion monitoring system}

Performance of the ICPW is evaluated using a corrosion-monitoring system and installing reference electrodes on selected piles.

\subsubsection{Reference electrodes}

For each of the monitored project piles, silver/ silver chloride reference electrodes are placed at three different locations. The ones specified for this project have a robust construction cased in a nonconductive material that is electrically insulating and suitable for permanent embedment and exposure in highly alkaline conditions such as those encountered in concrete.

The electrodes have a possible service life in excess of 25 years based upon encapsulation in concrete and interrogation of up to once per week on average for 1 hour with instrumentation of $10 \mathrm{Mohm}$ input impedance or greater. They also have a predicted accuracy of $\pm 10 \mathrm{mV}$ over their service life and an accuracy of $\pm 3 \mathrm{mV}$ over any 24 hour period.

\subsubsection{Remote monitoring unit}

The corrosion-monitoring system employs a remote monitoring unit (RMU) mounted on each dolphin structure. Each RMU has a battery powered microcontroller used to perform electric potential and anode current output measurements. It also controls relay switching so that instant-off and depolarization measurements can be obtained. The units are designed with the necessary additional components to collect and store test data from the monitored piles. The RMUs also transmit data via radio wave to a land-based main control unit (MCU).

The RMUs are housed in weatherproof cabinets, manufactured from glassreinforced plastic (GRP) with an internal classification of NEMA 4X. The 
cabinets are designed to protect the internal components from corrosion in the marine environment. The contractor's design specification permits no penetration to be made to the cabinets except when made with the appropriate polyvinyl chloride (PVC) couplings or box adapters. All penetrations were sealed with a silicone sealant.

The cabinet interiors were equipped with temperature and humidity sensors to monitor interior conditions for the purpose of assessing the potential for corrosion to the internal components. The specification also required that all entries for wiring be located in the bottom of the cabinets and all external screws, nuts, and locking washers were to be 316 grade stainless steel. The monitoring circuit requires minimal power consumption, with the power supply consisting of a $12 \mathrm{~V}$ rechargeable battery powered with a $24 \mathrm{~W}$ photovoltaic (PV) solar panel. To better protect the RMUs from damage, they were to be mounted on the west faces of the dolphin piers, which are opposite of the docking side.

\subsubsection{Main control unit}

The MCU provides the overall management of the corrosion monitoring system and is located in a secure area on land adjacent to the dolphins. It collects and stores the information transmitted from the RMUs. In the event of a break in this communication, there is an onboard microprocessor within each RMU that operates the system using the same parameters set within the MCU. The MCU also provides user accessibility via a highspeed Internet connection.

The unit performs the following functions through onboard programmed protocols:

- instant-off (time programmable)

- data logging interval (selectable)

- depolarization test (selectable [1 month, 3 month or 6 month])

- date and time stamp.

Like the RMUs, the MCU cabinet was weatherproof. All entries for wiring were to be located in the bottom of the external enclosure, and all external screws, nuts, and locking washers were to be 316 grade stainless steel. 


\subsubsection{Electrical equipment}

The contractor provided specifications for all wiring and cabling; electrical conduit and fittings; and junction boxes that were to be used for the CP and corrosion monitoring systems.

All wiring and cabling used in the installation was coated with HMWPE insulation. The installation of the electrical wiring leading from the anodes was to be incorporated within the composite wrap up to surface-mounted PVCjunction boxes. Monitoring and CP circuit cables were routed to the RMUs in chases cut within the concrete and PVC conduit.

The PVC electrical conduit is schedule 80 and conforms to NEMA standards Publication TC2-Max 90 . The conduit fittings meet NEMA TC3. Solvent cement for attaching fittings to the conduit was supplied or recommended by the conduit manufacturer.

For non instrumented piles, $3 / 4$ in. diameter conduit was required. For instrumented piles, the contractors design called for $1 \mathrm{in}$. diameter conduit, allowing for the additional cabling. All junction boxes, which were to be installed around the structure to allow collection of the DC field cabling, were specified to be watertight and manufactured in PVC. All attachments to the concrete surface were made with nonmetallic hardware Fisher Type Hammerfix N6 x 40 FN.

\subsection{Installation of the technology}

The installation of the ICPW system required two crews - a dive crew and a CP installation crew. Close coordination between the two was important during the preparation as well as the actual installation phases.

\subsubsection{Structure preparation}

Before installing any system components on the two dolphin piers, it was necessary to clean the excessive amount of marine growth on the piles. All surfaces of the project piles, starting from the top and extending down to about $10 \mathrm{ft}$, were cleaned. The work was accomplished by the project dive crew using pole scrapers and brushes. Once cleaned, the surfaces were inspected for exposed surface metals that could cause short circuiting of the anode to the reinforcement steel. This was performed through visual ob- 
servation and use a pachometer. All exposed metals were marked and either completely removed from the surface or isolated.

Using design drawings, the following locations were marked onto the concrete surfaces of the piles in a permanent manner:

- continuity holes for attaching wire leads to reinforcement tendons

- cathode locations

- anode elevations

- reference electrode locations.

While the dive crew prepared the piles, the contractor's CP installation crew performed other preparation tasks. They assembled aprons consisting of eight of the individual zinc mesh strips spaced to properly align with a pile face when wrapped around the octagonal pile (Figure 6). The sheets were attached by soldering a $0.75 \mathrm{in}$. strip of anode-grade zinc around the top of all sheets, with a "tag" end remaining for attachment to a 14 AWG HMWPE anode cable. The compression panels were cut to the correct length and the longitudinal grooves were cut on one face. The CP installation crew also field-calibrated the reference electrodes to ensure that the cells functioned according to the design specifications.

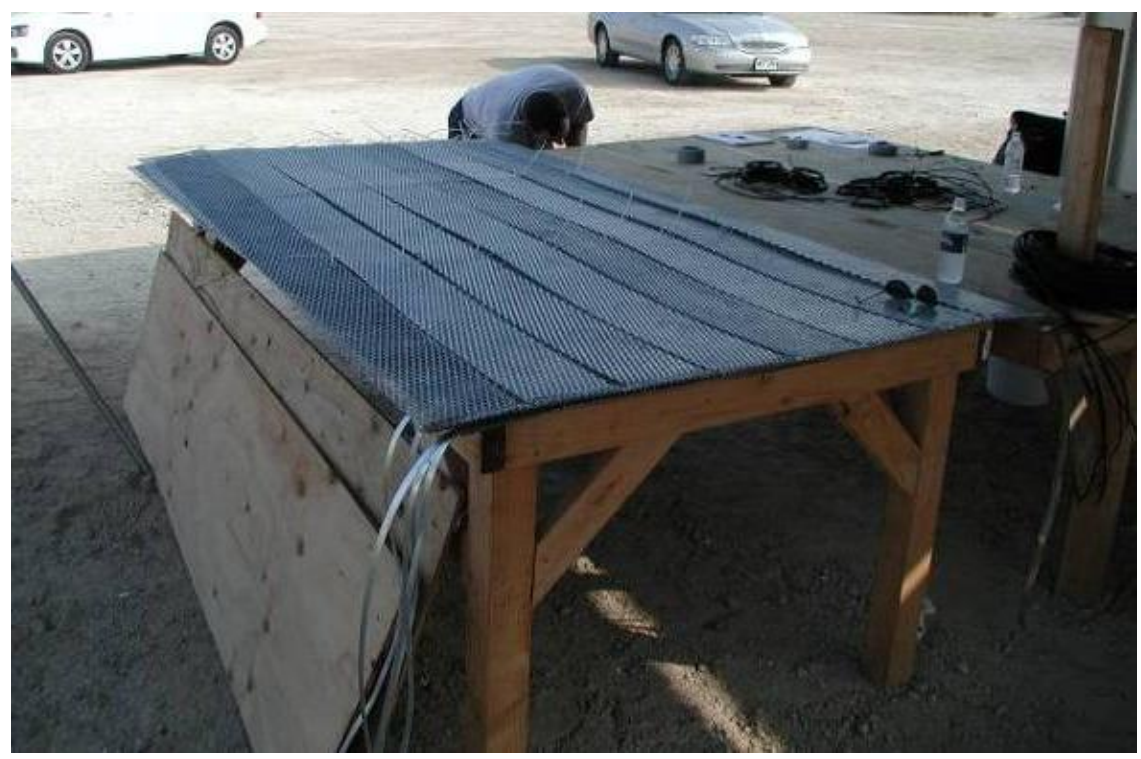

Figure 6. Assembled apron of eight mesh anode strips. 


\subsubsection{System installation}

After the piles were cleaned and the crew completed the shore-side preparation activities, installation work at the two dolphins began. The CP installation crew constructed temporary rafts to transport themselves as well as components, materials, and tools from the shore to the piers. These floating rafts (Figure 7) were bottomless boxes constructed of plywood encasing one or more large chunks of polystyrene. Additional rafts were constructed and braced between piles to provide working platforms beneath the dolphin structures.

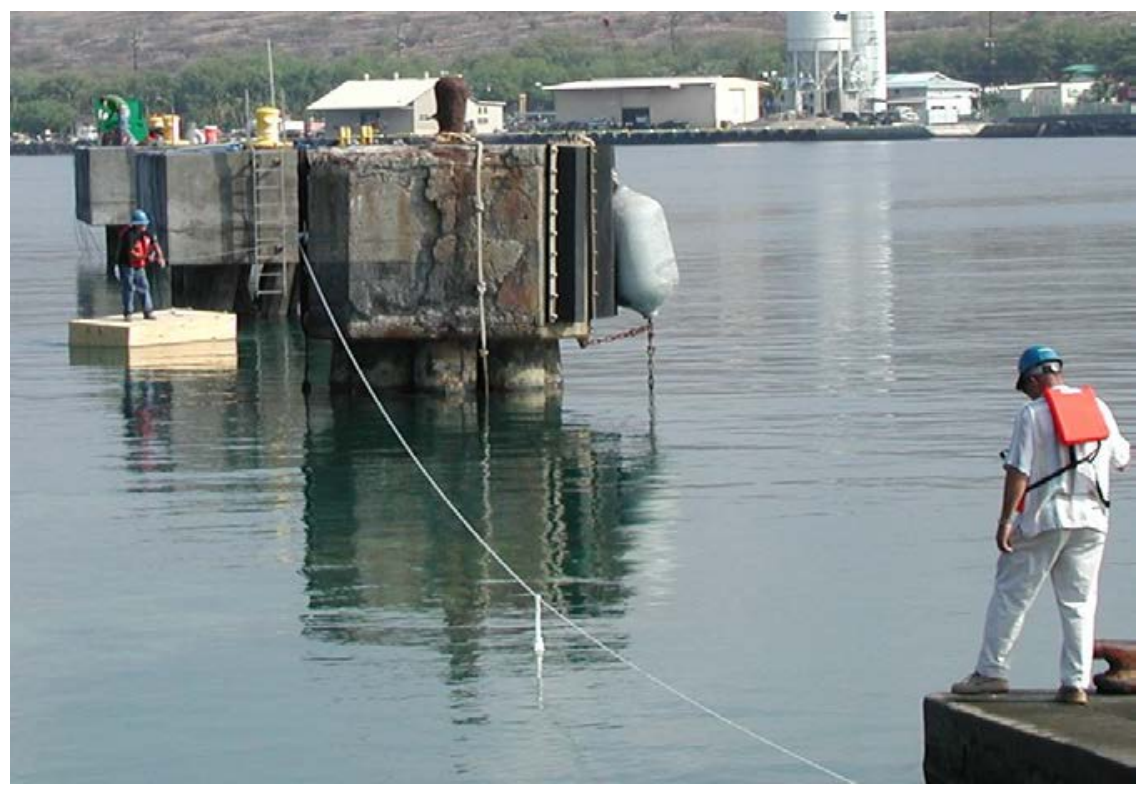

Figure 7. Floating raft used to transport materials and crew.

\subsubsection{Bulk zinc anode}

On each of the protected piles, the dive crew installed a bulk zinc anode assembly at the $-8.0 \mathrm{ft}$ elevation. The anode was clamped to the pile using a 2 in. galvanized steel channel (Figure 8) with the flanged side placed against the pile surface and two hot-dip galvanized carriage bolts of $5 / 8$ in. diameter extending to the anode. The anode connector cable was attached to the steel strap core, which was connected to the assembly. The cable, which would later be connected at the other end to the RMU, was temporarily secured to the pile using nylon ties. 


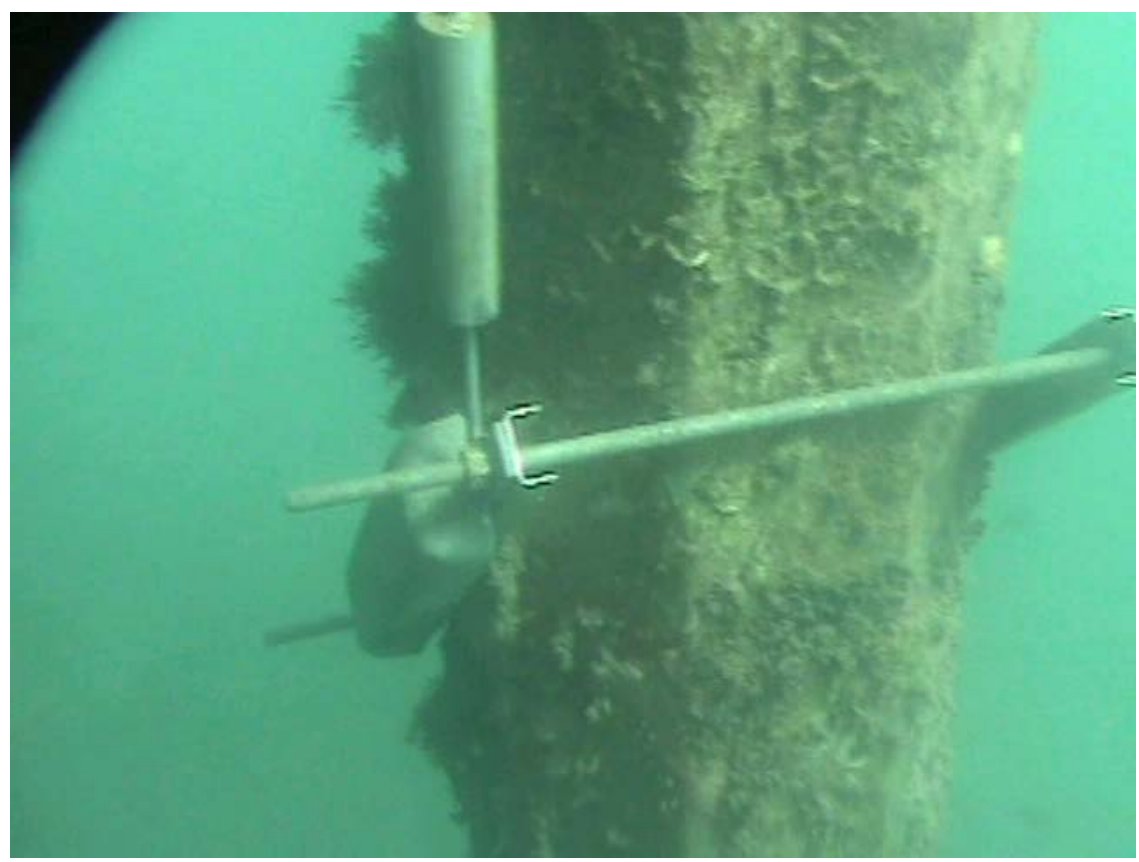

Figure 8. Bulk anode installed at $-8.0 \mathrm{MSL}$ elevation.

\subsubsection{Electrical continuity of steel tendons}

Prior to the installation of the system, electrical continuity testing was performed on one of the spare piles left over from construction of the dolphins. Plugs of concrete were removed to expose two of the individual reinforcement tendons and the spiral tie. The spiral tie was found to be epoxy-coated, thereby preventing continuity between the tendons. This was confirmed later by additional testing of in-place piles. Electrical continuity would need to be established between the individual reinforcement strands for the CP system to work effectively.

To achieve electrical continuity on the piles that were to receive $\mathrm{CP}$, a concrete plug was removed above each tendon, about $16 \mathrm{in}$. below the top of the pile (Figure 9). Tendon locations were determined using a pachometer. A square groove was cut horizontally along the faces of the pile and between the plugs to allow for the connection of a $1 / 8$ in. diameter steel rod. Excavation of the concrete for both the plugs and the grooves was accomplished with a jackhammer powered by a generator placed on the top deck of the pier.

For each pile, the steel rod was welded to each of the exposed tendons and spiral tie. Next, two negative connections to steel were made. Each connection consisted of a 14 AWG cable connected to a 3/ 16 in. diameter steel 
tube soldered to the bared end of the cable. The tube was flattened and then welded to the spiral tie or tendon. The joint between the wire insulation and steel tab was coated with a waterproof rubberized liquid electrical coating. The welds were cleaned, and continuity verification measurements were taken between all reinforcing and negative connection wires.

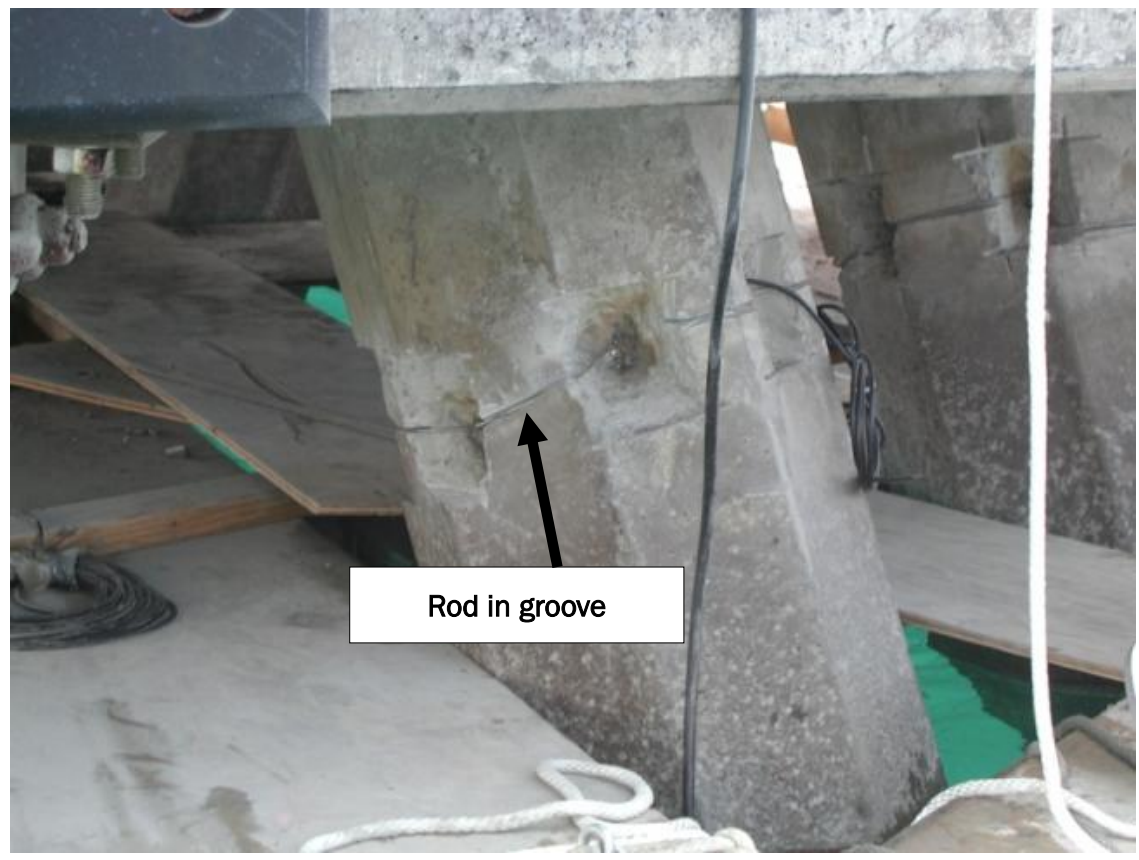

Figure 9. Plugs removed and steel rod placed in grooves.

The welds were then coated with spray-applied cold-galvanizing compound. All holes and grooves were filled to the original profile with the mortar. The use of the mortar was a modification to an original design that used an epoxy-encapsulation. This change was made to prevent complications associated with connections being exposed to seawater splash during high tide; and to reduce potential problems associated with applying epoxy-coating in confined spaces.

The procedures used to make the electrical connections have the following benefits: (1) the connections were all steel-to-steel welds, (2) cold galvanizing minimized corrosion of the welds before full $\mathrm{CP}$, and (3) the connections were located near the pile to be wrapped to provide protecion by the wrap. 


\subsubsection{Reference electrodes}

After electrical continuity was established, the reference electrodes were installed. For piles designated for corrosion monitoring, three reference electrodes per pile were installed at approximate elevations of $+2.00 \mathrm{ft}$ MSL (R1), -10.00 ft MSL (R2), and -20.00 ft MSL (R3). The R1 reference electrodes were the only ones installed within the wrapped section. For those, a $2.00 \times 4.00$ in. hole to the depth of the steel was excavated in the concrete with care taken not to expose any reinforcement. The reference electrodes were placed in excavations with the cables already having been attached. Each excavation was then filled with the same premixed mortar that was used for electrical continuity excavations. For the remaining R1 and $\mathrm{R} 2$ reference electrodes that required underwater installation, the dive crew attached them to the concrete surface of the piles using nylon straps. The attached cables were secured to the piles using the same procedure.

For each monitored pile, a separate third negative connection to the steel reinforcement was established specifically for use with the reference electrodes. This connection was made using the same procedure described for the CP cathodes.

Electrical potentials were measured with respect to the permanently installed reference electrodes within 1 hour and within 24 hours of embedment in seawater. Measurements were taken at low (10 - 20 Mohms) and high (500 - 1000 Mohms) input impedance to determine whether the contact resistance of all the reference electrodes to the concrete was above the designed value. Potential shifts less than $\pm 3 \mathrm{mV}$ in 24 hours were considered acceptable.

\subsubsection{Zinc mesh anodes and compression panels}

After the bulk anodes and reference electrodes were in place, the dive crew was able to begin installing the zinc mesh anode aprons and compression panels (Figure 10). This process required the use of a temporary work platform affixed to the pile at the $-5.5 \mathrm{ft}$ elevation. The platform, consisting of fabricated friction collars with a plywood deck, enabled the divers to place the zinc mesh and compression panels at the required elevation. 


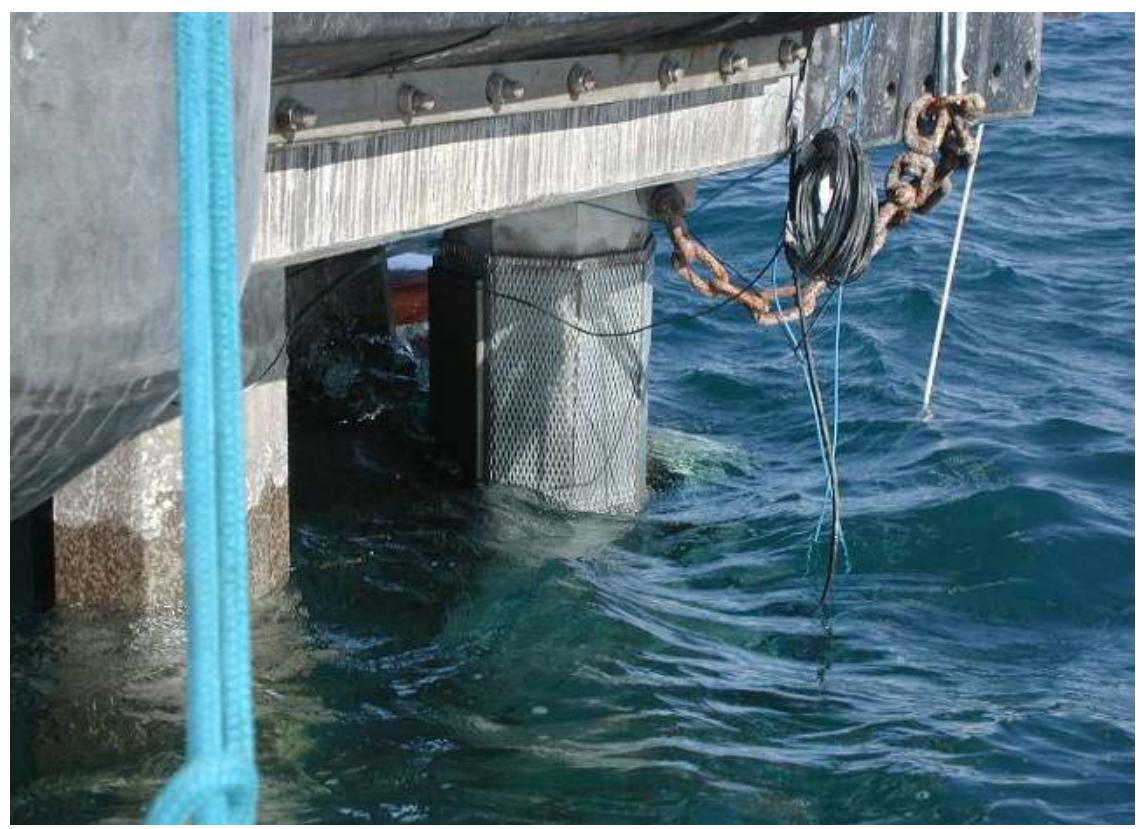

Figure 10. Anode assembly positioned against pile.

Each apron assembly, once set into position, was held in place using plastic tie wraps. The divers placed a compression panel against each of the eight pile faces (Figure 11) and used elastic cords to temporarily hold them in place. The panels were permanently secured with stainless steel banding affixed at $1 \mathrm{ft}$ increments from top to bottom. Next, the dive crew removed the work platform and routed the cable leading to the bulk anode through a piece of conduit placed between two adjacent compression panels.

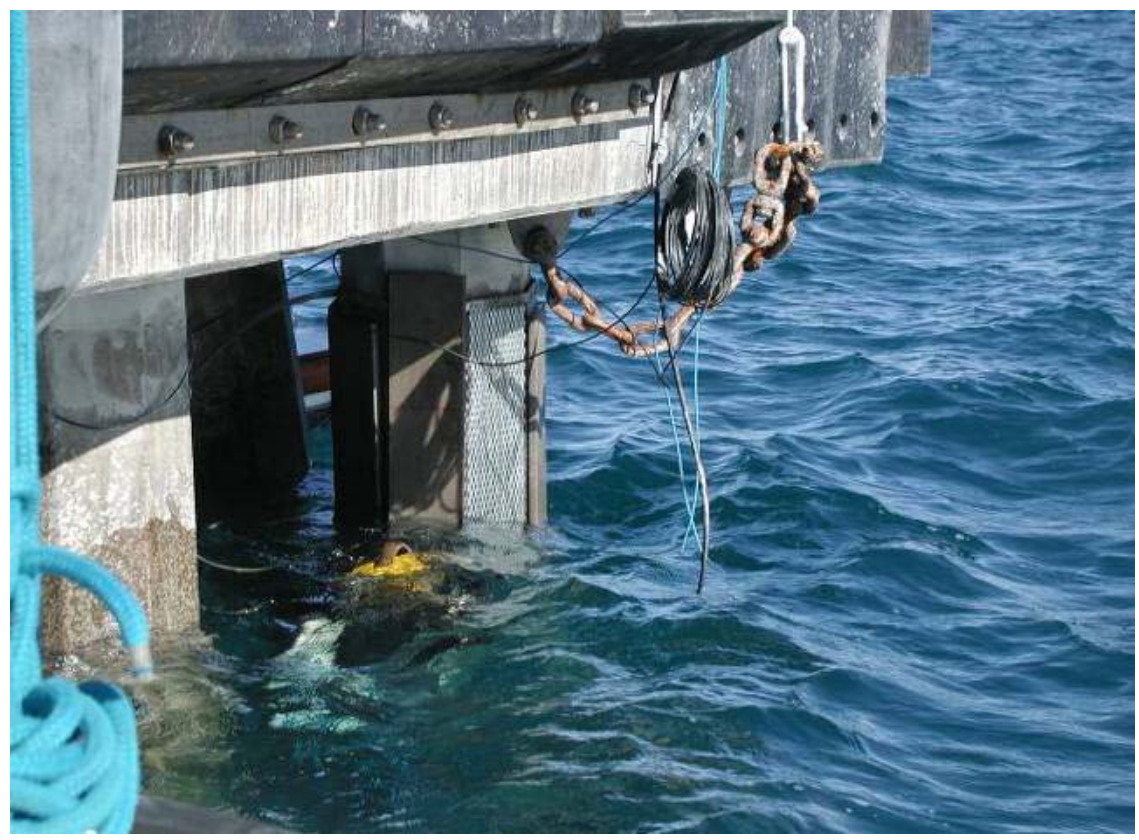

Figure 11. Diver placing compression panel over anode assembly. 


\subsubsection{Composite wrapping material}

The composite wrapping material installation did not start until all zinc mesh/ compression panel assemblies were installed for both piers. At that time, the assemblies were cleaned to remove any new marine growth. After any existing sharp corners or edges were removed, a primer was applied to the exterior surface of assemblies. The divers performed this work by hand, using protective gloves and brushes.

For each pile, the divers removed the wrap material from the sealed bag and applied it by winding tangentially around the pile to cover the assembly. The wrap was applied in a manner to provide three plies of coverage. For portions of the application that were above the waterline, water was sprayed on each layer of material as it was being installed. As prescribed by the system manufacturer, a stricture band made of plastic sheeting was then placed around the composite wrap to remain during initial curing and help ensure compression against the pile. The sheeting was perforated with a special tool to prevent carbon dioxide build-up beneath it. Once the composite hard to the touch through the plastic, the sheeting was removed and the wrap was allowed to cure for three more days. The wrapped area was then coated using the same primer that was applied beneath the wrap. The finished composite wrap assembly is shown in Figure 12.

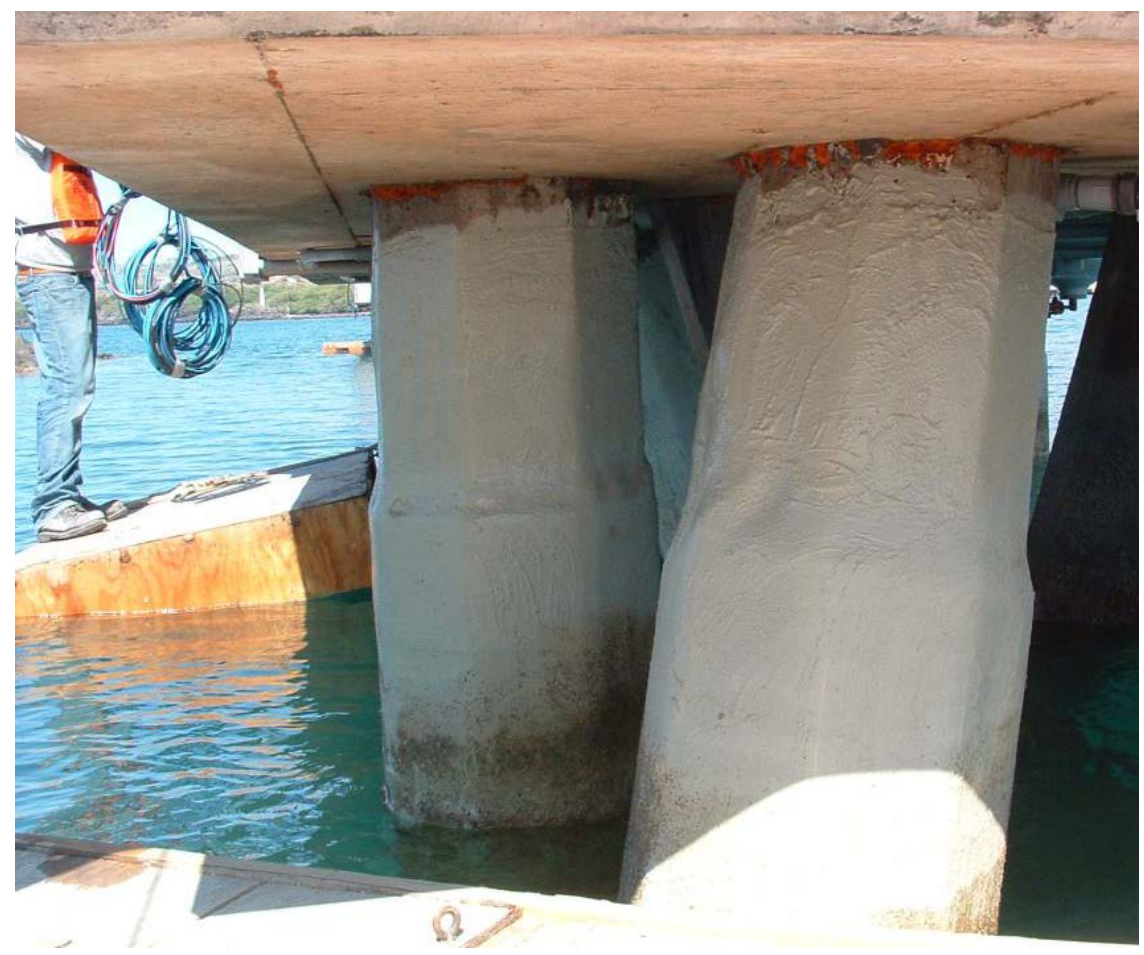

Figure 12. Finished composite wrap assembly. 


\subsubsection{Wiring, conduit, RMUs, and MCU}

The crew performed the wiring runs and installed the electrical conduit that housed them immediately after the project piles were wrapped and primed to protect them from mechanical damage and vandalism.

The RMUs and PV power panels were installed on the west face of each dolphin (Figure 13), opposite the landing area. The west face was least susceptible to damage and provided adequate sunlight for the PV power. All conduits were routed to the RMUs in a manner to reduce the number of openings and wire pulls. The conduits and junction boxes were secured to concrete surface on the undersides of the dolphins (Figure 14). Nylon fasteners were used to attach the junction boxes. The same fasteners in combination with PVC straps, spaced every 12 in., were used to attach the conduit. Splices were avoided for all wiring except for the zinc strap/ wiring transition for the zinc mesh connection.

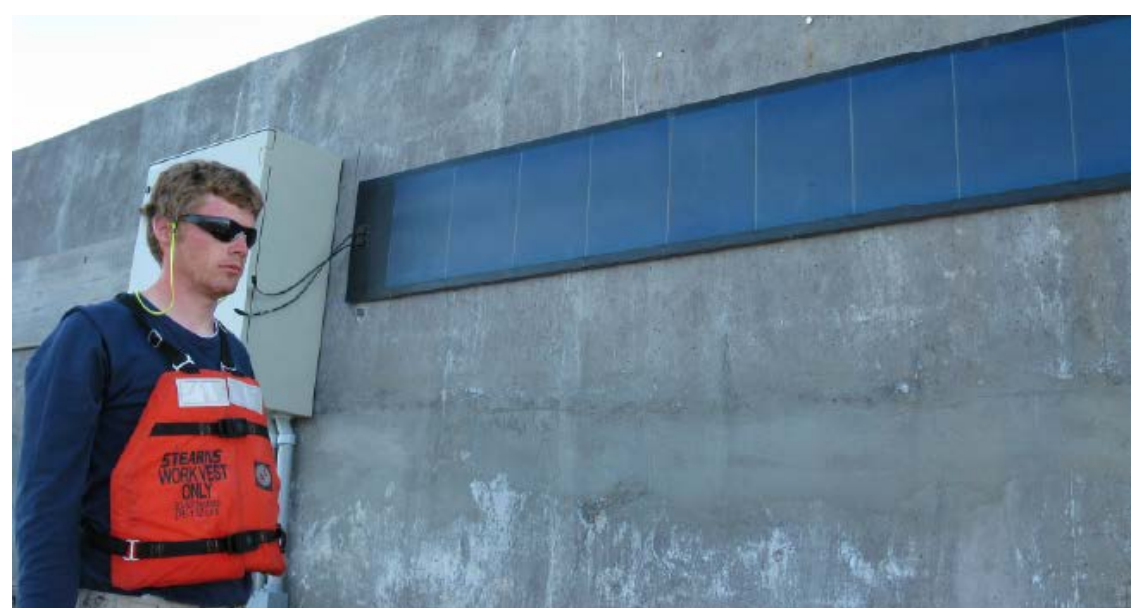

Figure 13. RMU and PV panel mounted on west face of dolphin pier.

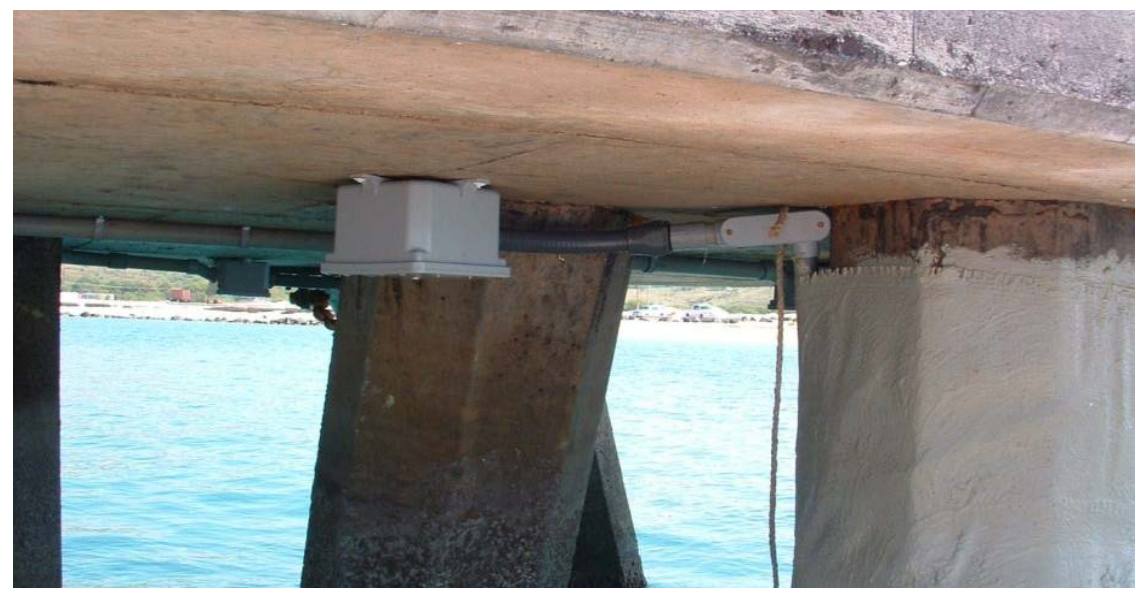

Figure 14. Junction box and conduit attached to underside of pier. 
The MCU was mounted on a permanent pole located on shore inside a designated secure area within the immediate vicinity.

\subsubsection{Pre-commissioning testing}

During the installation and before commissioning of the completed system, the contractor performed necessary testing. After the anode systems were in place, the anode/ cathode resistances were monitored to determine whether short circuits had been established. Any that were detected were located and corrected before further work began. Polarity and continuity checks were made on all circuits. Insulation checks were undertaken prior to connections to either anode or reinforcement. These checks verified electrical isolation of DC positive cables from DC negative cables.

\subsection{Technology operation and monitoring}

Upon completion of the pre-commissioning testing, the CP installation crew commissioned the CP system. The procedures, which were established as part of the system design, included the following steps:

1. visual inspection of the circuits, RMUs, MCU, and other CP components

2. energizing of electrical circuits and equipment previously inspected, tested, and judged satisfactory and safe to energize

3. initial performance assessment, interpretation of performance assessment data

4. initial performance assessment and verification

5. performance assessment after 1 year.

\subsubsection{Visual inspection}

The CP system and all of its components were subjected to complete visual inspection to confirm that they were properly installed, labeled, and protected.

\subsubsection{Initial energizing and adjustments}

The system was not energized until the composite wraps were in place for at least 14 days. At that time, the CP system was energized initially not exceed $10-20 \%$ of design current capacity. The following measurements were made and recorded: 
- the potential of the steel/ concrete with respect to all permanently installed reference electrodes at any locations determined in the design method statements or specification

- the output voltage and current values of all piles

- confirmation that polarity of all values conforms to the contractor's design document and that the steel/ concrete potentials, measured against all permanently installed reference electrodes, shift in a negative direction.

\subsubsection{Initial performance testing and verification}

The initial performance testing began after energizing the system. The following tasks were performed:

- measurement of instant-off (IR free) potentials at all permanently installed reference electrodes a short time after switching open circuits of the anode system to the reinforcement

- measurement of potential decay after switching the CP anode open circuit

- measurement of parameters from all other sensors installed as part of the performance monitoring system

- measurement of steel/ concrete on-potentials (including IR drop).

The data collected were reviewed and interpreted by a cathodic protection specialist to ensure that the $\mathrm{CP}$ system was delivering enough current to meet the requirements of the contractor's design document. The potential decay and shift were measured at all embedded reference electrodes. The anode currents and voltages also were recorded. The data for Dolphin 2 and Dolphin 3 are shown in Table 1 and Table 2, respectively. 
Table 1. Initial CP performance data for Dolphin 2.

\begin{tabular}{|c|c|c|c|c|c|c|c|c|}
\hline Pile & Protection & I-Bulk (mA) & $\begin{array}{l}\text { Current- } \\
\text { Mesh } \\
(\mathrm{mA})\end{array}$ & \begin{tabular}{|l} 
I-System \\
(mA)
\end{tabular} & $\begin{array}{l}\text { Reference } \\
\text { Cell }\end{array}$ & $\begin{array}{l}\text { Native Potential } \\
(\mathrm{Ag} / \mathrm{AgCl}) \\
(\mathrm{mV})\end{array}$ & $\begin{array}{l}\text { Instant Off } \\
\text { Potential } \\
(\mathrm{Ag} / \mathrm{AgCl}) \\
(\mathrm{mV})\end{array}$ & $\begin{array}{l}\text { Change In } \\
\text { Potential } \\
\text { (mV) }\end{array}$ \\
\hline \multirow{3}{*}{1} & \multirow{3}{*}{ Full ICPW } & \multirow{3}{*}{56.0} & \multirow{3}{*}{30.5} & \multirow{3}{*}{56.0} & R1 & -57 & -433 & -376 \\
\hline & & & & & R2 & -430 & -751 & -321 \\
\hline & & & & & R3 & -427 & -777 & -350 \\
\hline \multirow{3}{*}{3} & \multirow{3}{*}{ Full ICPW } & \multirow{3}{*}{64.2} & \multirow{3}{*}{35.0} & \multirow{3}{*}{68.5} & R1 & -439 & -630 & -191 \\
\hline & & & & & R2 & -438 & -680 & -242 \\
\hline & & & & & R3 & -425 & -722 & -297 \\
\hline \multirow{3}{*}{11} & \multirow{3}{*}{ Full ICPW } & \multirow{3}{*}{83.0} & \multirow{3}{*}{37.0} & \multirow{3}{*}{84.0} & $\mathrm{R} 1$ & -47 & -324 & -277 \\
\hline & & & & & R2 & -428 & -640 & 212 \\
\hline & & & & & R3 & -444 & -643 & -199 \\
\hline \multirow{3}{*}{13} & \multirow{3}{*}{$\begin{array}{l}\text { Wrap with } \\
\text { No CP }\end{array}$} & \multirow{3}{*}{ N/A } & \multirow{3}{*}{ N/A } & \multirow{3}{*}{ N/A } & $\mathrm{R} 1$ & -431 & N/A & N/A \\
\hline & & & & & R2 & -413 & N/A & N/A \\
\hline & & & & & R3 & -412 & N/A & N/A \\
\hline \multirow{3}{*}{15} & \multirow{3}{*}{$\begin{array}{l}\text { No Wrap } \\
\text { and No CP }\end{array}$} & \multirow{3}{*}{ N/A } & \multirow{3}{*}{ N/A } & \multirow{3}{*}{ N/A } & R1 & -437 & N/A & N/A \\
\hline & & & & & R2 & -437 & N/A & N/A \\
\hline & & & & & R3 & -390 & N/A & N/A \\
\hline \multirow{3}{*}{17} & \multirow{3}{*}{$\begin{array}{l}\text { Wrap and } \\
\text { Bulk Anode }\end{array}$} & \multirow{3}{*}{37.7} & \multirow{3}{*}{ N/A } & \multirow{3}{*}{37.7} & R1 & -405 & -418 & -13 \\
\hline & & & & & $\mathrm{R} 2$ & -489 & -668 & -179 \\
\hline & & & & & R3 & -488 & -642 & -154 \\
\hline \multirow{3}{*}{21} & \multirow{3}{*}{ Full ICPW } & \multirow{3}{*}{91.0} & \multirow{3}{*}{39.0} & & R1 & -446 & -577 & -131 \\
\hline & & & & 94.9 & R2 & -444 & -620 & -176 \\
\hline & & & & & R3 & -449 & -750 & -301 \\
\hline
\end{tabular}


Table 2. Initial CP performance data for Dolphin 3.

\begin{tabular}{|c|c|c|c|c|c|c|c|c|}
\hline Pile & Protection & I-Bulk (mA) & $\begin{array}{l}\text { I-Mesh } \\
(\mathrm{mA})\end{array}$ & $\begin{array}{l}\text { I-System } \\
\text { (mA) }\end{array}$ & $\begin{array}{l}\text { Reference } \\
\text { Cell }\end{array}$ & $\begin{array}{l}\text { Native Potential } \\
\text { (Ag/AgCl) } \\
(\mathrm{mV})\end{array}$ & $\begin{array}{l}\text { Instant Off } \\
\text { Potential } \\
\text { (Ag/AgCl) } \\
(\mathrm{mV})\end{array}$ & $\begin{array}{l}\text { Change In } \\
\text { Potential } \\
(\mathrm{mV})\end{array}$ \\
\hline \multirow{3}{*}{2} & \multirow{3}{*}{ Full ICPW } & \multirow{3}{*}{31.1} & \multirow{3}{*}{19.2} & \multirow{3}{*}{35.1} & R1 & -556 & -690 & -134 \\
\hline & & & & & R2 & -523 & -806 & -283 \\
\hline & & & & & R3 & -520 & -837 & -317 \\
\hline \multirow{3}{*}{4} & \multirow{3}{*}{ Full ICPW } & \multirow{3}{*}{54.2} & \multirow{3}{*}{25.1} & \multirow{3}{*}{59.9} & $\mathrm{R} 1$ & -327 & -704 & -377 \\
\hline & & & & & R2 & -374 & -731 & -357 \\
\hline & & & & & R3 & -372 & -739 & -367 \\
\hline \multirow{3}{*}{12} & \multirow{3}{*}{ Full ICPW } & \multirow{3}{*}{47.0} & \multirow{3}{*}{25.3} & \multirow{3}{*}{55.0} & R1 & -427 & -789 & -362 \\
\hline & & & & & R2 & -405 & -782 & -377 \\
\hline & & & & & R3 & -406 & -774 & -368 \\
\hline \multirow{3}{*}{14} & \multirow{3}{*}{$\begin{array}{l}\text { Wrap with } \\
\text { No CP }\end{array}$} & \multirow{3}{*}{$\mathrm{N} / \mathrm{A}$} & \multirow{3}{*}{$\mathrm{N} / \mathrm{A}$} & \multirow{3}{*}{ N/A } & R1 & -487 & $\mathrm{~N} / \mathrm{A}$ & N/A \\
\hline & & & & & $\mathrm{R} 2$ & -471 & $\mathrm{~N} / \mathrm{A}$ & N/A \\
\hline & & & & & R3 & -469 & $\mathrm{~N} / \mathrm{A}$ & N/A \\
\hline \multirow{3}{*}{16} & \multirow{3}{*}{$\begin{array}{l}\text { No Wrap } \\
\text { and No CP }\end{array}$} & \multirow{3}{*}{$\mathrm{N} / \mathrm{A}$} & \multirow{3}{*}{$\mathrm{N} / \mathrm{A}$} & \multirow{3}{*}{ N/A } & R1 & -635 & $\mathrm{~N} / \mathrm{A}$ & N/A \\
\hline & & & & & R2 & -634 & $\mathrm{~N} / \mathrm{A}$ & N/A \\
\hline & & & & & R3 & -431 & $\mathrm{~N} / \mathrm{A}$ & N/A \\
\hline \multirow{3}{*}{17} & \multirow{3}{*}{$\begin{array}{l}\text { Wrap and } \\
\text { Bulk Anode }\end{array}$} & \multirow{3}{*}{50.5} & \multirow{3}{*}{ N/A } & \multirow{3}{*}{50.5} & $\mathrm{R} 1$ & -360 & -349 & +11 \\
\hline & & & & & R2 & -362 & -794 & -432 \\
\hline & & & & & R3 & -361 & -787 & -426 \\
\hline \multirow{3}{*}{18} & \multirow{3}{*}{ Full ICPW } & \multirow{3}{*}{53.4} & \multirow{3}{*}{27.0} & & R1 & -372 & -562 & -190 \\
\hline & & & & 56.2 & R2 & -410 & -752 & -342 \\
\hline & & & & & R3 & -410 & -433 & -23 \\
\hline
\end{tabular}




\section{Discussion}

\subsection{Metrics}

The materials and components incorporated into the design were compliant with applicable standards and criteria specified in the following sources:

- National Electrical Code (NEC)

- American Society for Testing and Materials (ASTM)

- National Electrical Manufactures Association (NEMA)

- American National Standards Institute (ANSI).

The metric for evaluating the level of corrosion protection provided by the demonstrated technology was NACE SP0290-2007, "Cathodic Protection of Steel in Atmospherically Exposed Concrete Structures." The specific pertinent criteria were the following:

- A polarization of the reference electrode from its starting potential (native) to an instant-off of at least - $100 \mathrm{mV}$ (except if the native is less negative than $200 \mathrm{mV}$ where the steel is in a passivated state and cannot corrode). During the operation of the system the reference electrode potentials are moved more negatively. The polarization is the difference between the native potential (unprotected) and the instant-off potential (obtained with the system in operation). The amount of change is to be in line with the above value.

- An instant-off potential (measured between $0.1 \mathrm{~s}$ and $0.4 \mathrm{~s}$ after switching the DC circuit open) more negative than $-720 \mathrm{mV}$ with respect to silver/ silver chloride reference electrode. If the reinforcing steel potential obtained with a silver/ silver chloride reference electrode is equal to or greater than the above then corrosion cannot occur at this potential and hence the steel is adequately protected.

- A potential decay over a maximum period of 24 hours of at least 100 $\mathrm{mV}$ from instant-off. The potential decay is the depolarization value achieved from shutting the CP system off and measuring the difference in potential from the start (instant-off) to the end of the test (24 hours. off).

- A potential decay over an extended period (typically 24 hours or longer) of at least $150 \mathrm{mV}$ from the instant-off subject to a continuing 
decay and the use of reference electrodes (not potential-decay sensors) for the measurement extended beyond 24 hours. The extended period is allowed to enable sufficient oxygen to reach the reinforcing steel as in some cases the rate of depolarization could be slow due to high levels of moisture within the concrete.

Any of these criteria can be used to determine CP effectiveness. There is no NACE standard for concrete in a marine environment, so the most relevant metric was determined to be NACE SP0169-2007 for steel immunity to corrosion.

\subsection{Results}

Data collected by the corrosion monitoring system during the first year have been analyzed to determine if the $\mathrm{CP}$ metrics are being met. These data include instant-off potentials measured relative to the individual reference electrodes and the anode output current. For the instrumented piles, as stated previously, R1 refers to the reference electrode placed at the highest elevation ( $+2 \mathrm{ft}$ above mean sea level) and embedded in the pile concrete within the wrapped section of pile. The other two reference cell electrodes were placed below the wrapped section of pile and against the concrete pile surface at approximate elevations of - $10.00 \mathrm{ft}$ (R2) and $-20.00 \mathrm{ft}(\mathrm{R} 3)$ with respect to mean sea level.

\subsubsection{Dolphin 2-monitored piles having full ICPW system}

For Dolphin 2, Piles 1, 3, 11, and 21 were outfitted with the full impact and corrosion protection wrap (ICPW) system implemented. Each received the composite wrap, and they had both the mesh anode placed within the wrap as well as the bulk anode placed on the lower section of the pile. Figure 15, Figure 17, Figure 19, and Figure 21 show the instant-off potentials for the three reference electrodes on the four individual piles.

For each of the piles, R1 (which is embedded within the concrete in the wrapped section of pile and above sea level) varies the most during the year compared to the readings for R2 and R3. This result is due to the wetting and drying effects related to moisture migration. Reference electrodes R2 and R3, placed below sea level, have readings with less variability.

If the instant-off potential readings over time from the individual reference electrodes are predominately more negative than $-720 \mathrm{mV}$, the CP cri- 
terion are being met. For all four monitored piles, the metric is being met for all but two reference electrodes. For Pile 1, R1 readings are in the range of -600 to - $700 \mathrm{mV}$. For Pile 11 (Figure 19), R2 has negative potential readings below $>500 \mathrm{mV}$, which would be unlikely in this type of application, so the reference electrode is considered to be faulty. For Pile 21 (Figure 21), R2 and R3 become erratic in their behavior after 10 months, but neither reference electrode has shown to be faulty.

The anode output currents measured for each of the monitored ICPW piles on Dolphin 2 can be seen in Figure 16, Figure 18, Figure 20, and Figure 22. Each of the output currents for Piles 1 and 3 shows a reduction in current demand from the initial energizing level, which begins to occur at about the fourth month of service. The reductions are most likely to be due to the existing corrosion cells and chloride levels within the concrete. As the $\mathrm{CP}$ system is changing the environment around the corrosion cells, less current will be required as the passivating film increases current resistance to the steel. The more corrosion cells there are, the longer it will take to stabilize the system output current.

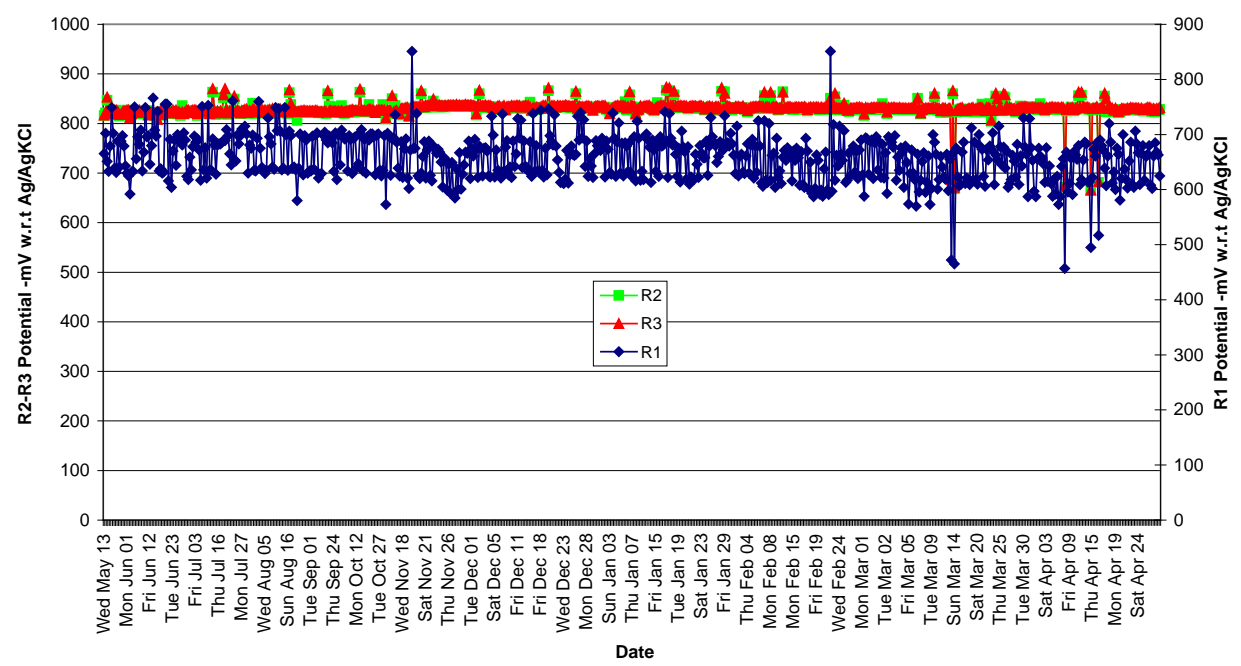

Figure 15. Instant-off potentials for first year, Dolphin 2, Pile 1 (full system). 


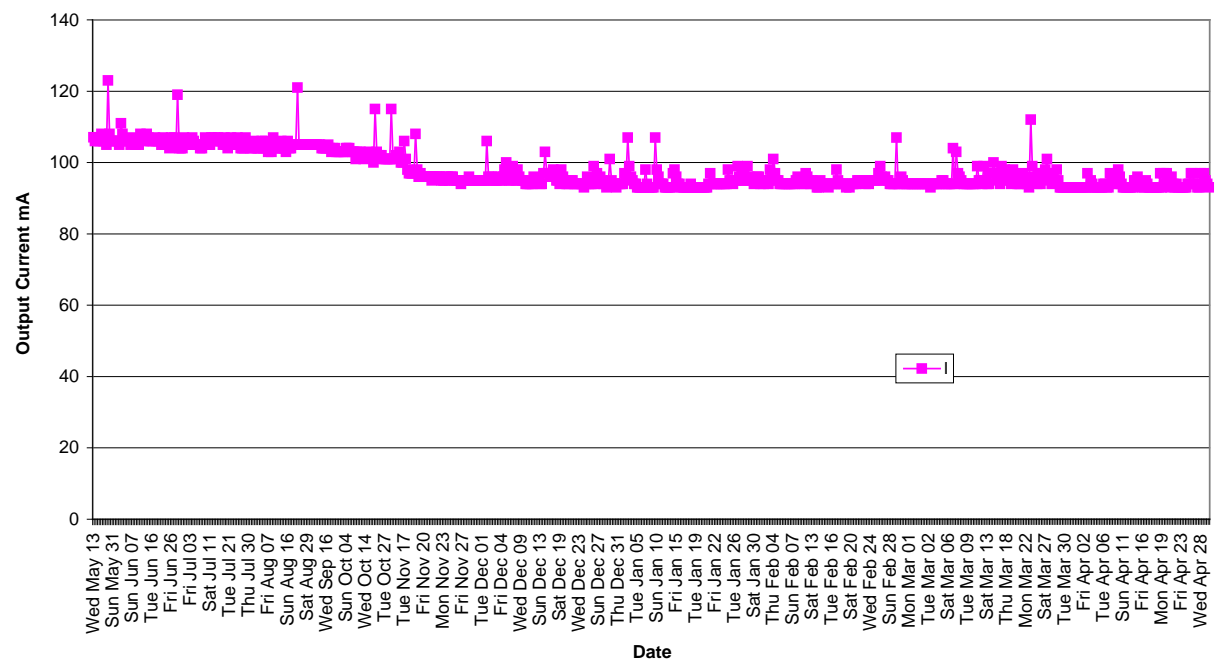

Figure 16. Output current for first year, Dolphin 2, Pile 1 (full system)

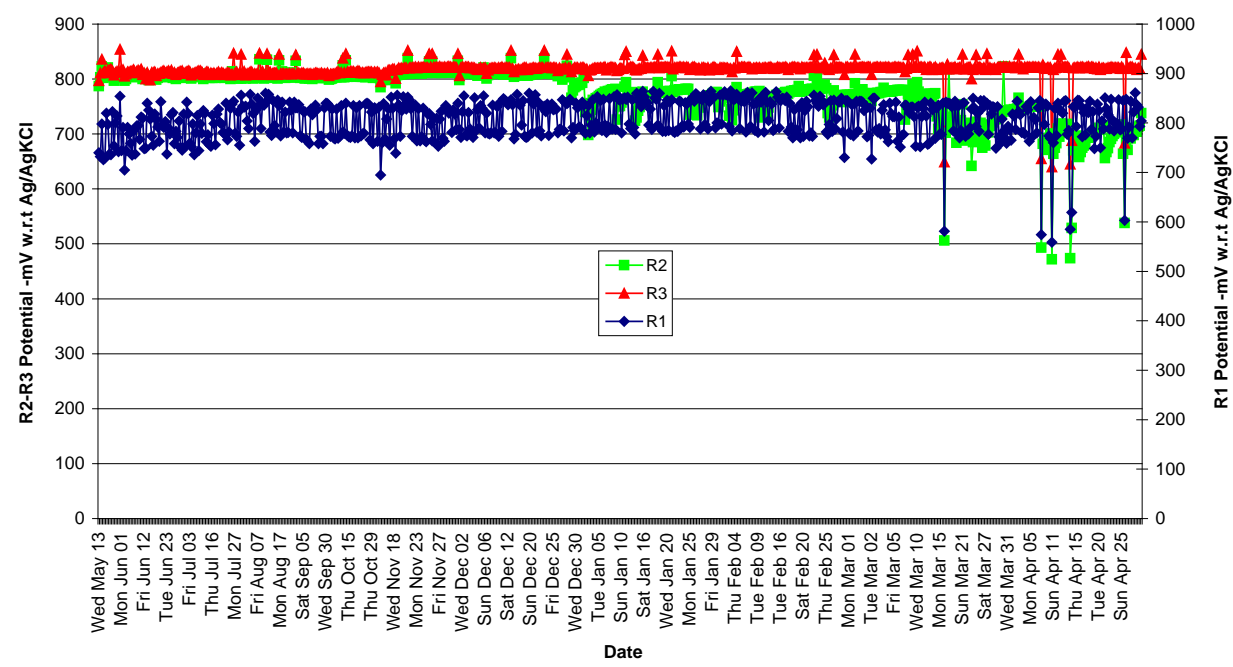

Figure 17. Instant-off potentials for first year, Dolphin 2, Pile 3 (full system).

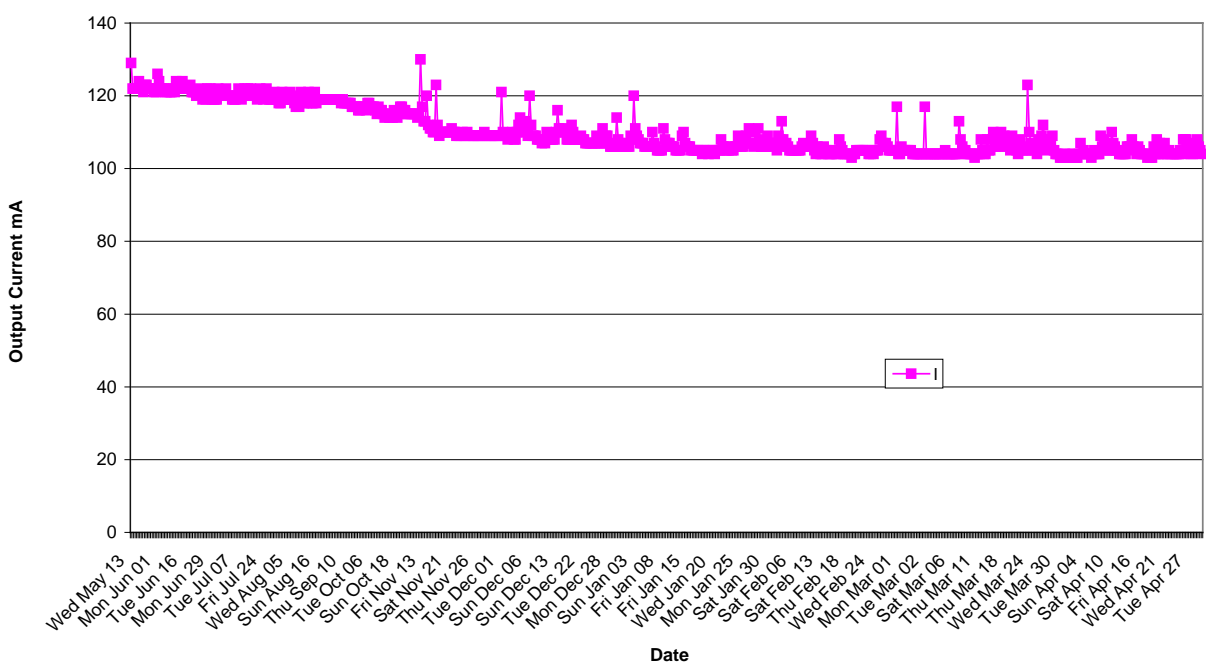

Figure 18. Output current for first year, Dolphin 2, Pile 3 (full system). 


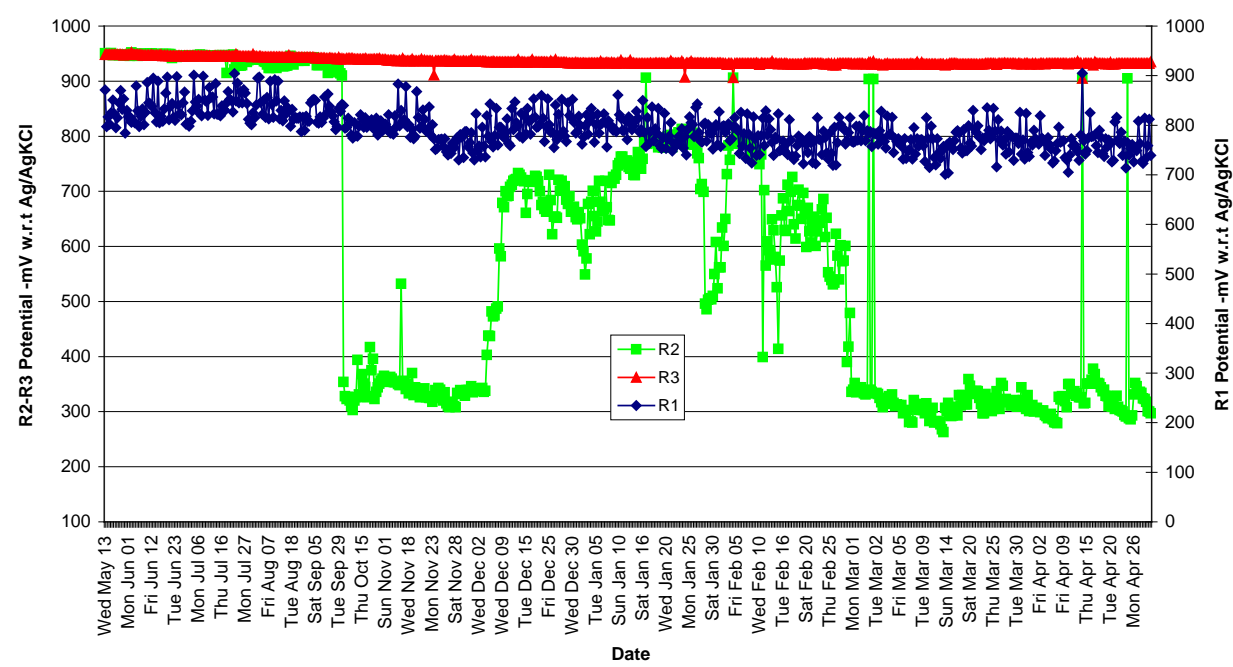

Figure 19. Instant-off potentials for first year, Dolphin 2, Pile 11 (full system).

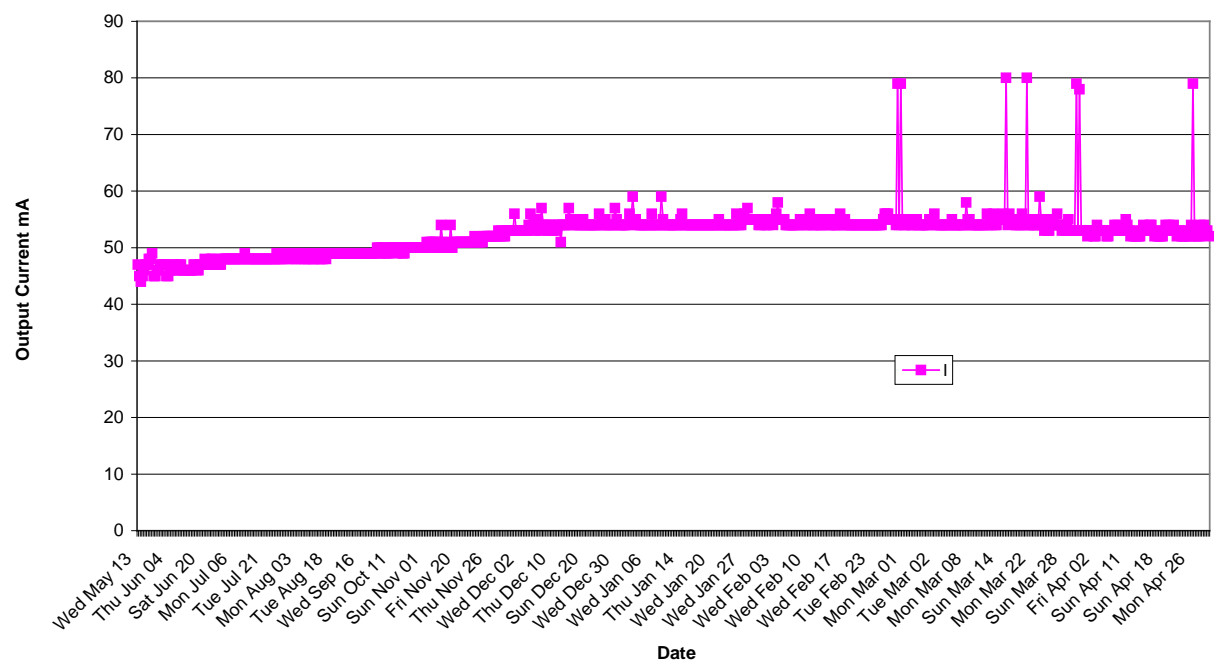

Figure 20. Output current for first year, Dolphin 2, Pile 11 (full system).

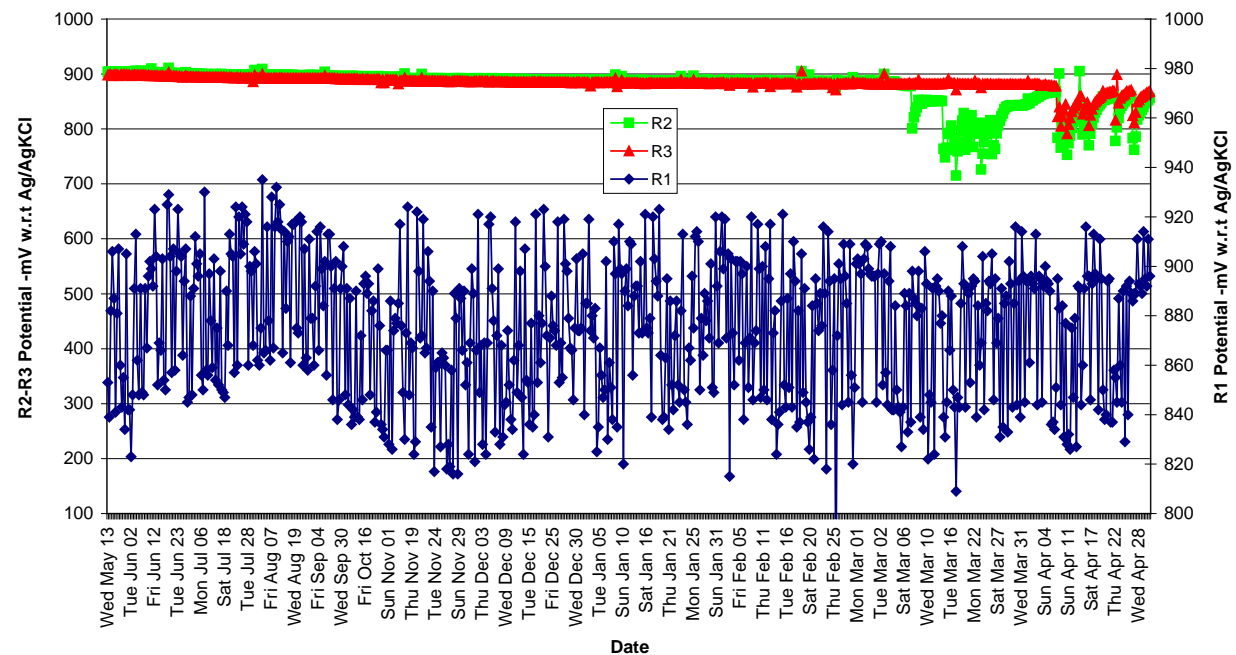

Figure 21. Instant-off potentials for first year, Dolphin 2, Pile 21 (full system). 


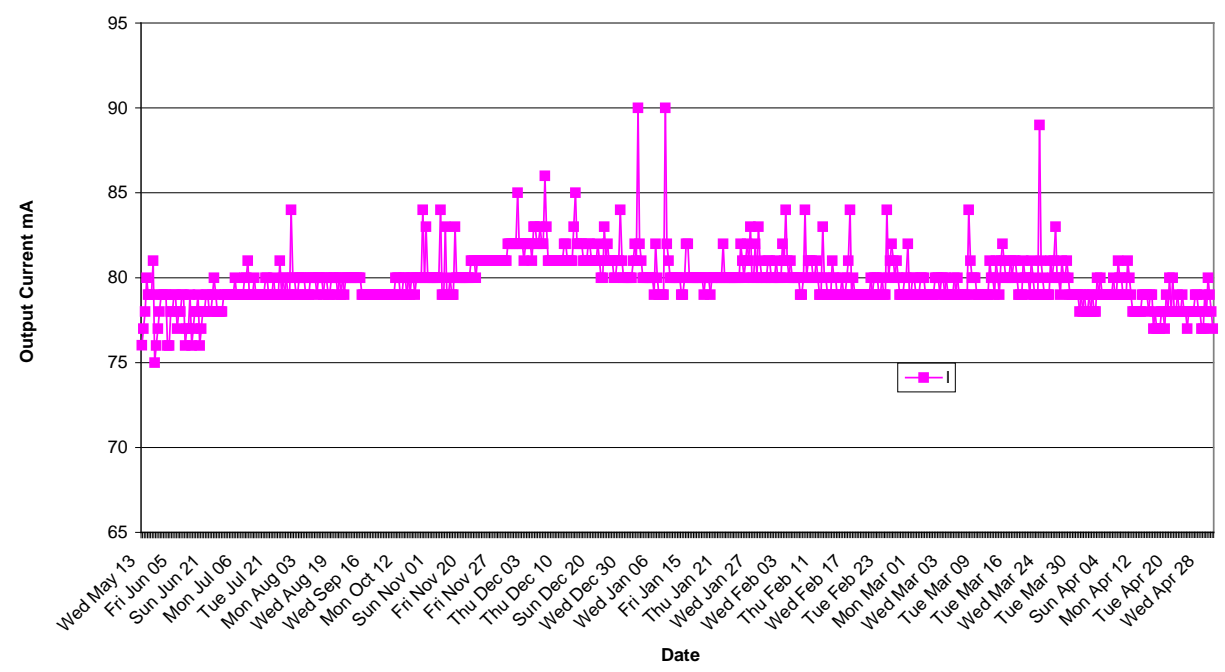

Figure 22. Output current for first year, Dolphin 2, Pile 21 (full system).

The output current for Pile 11 shows an increase in current demand from the initial energizing level. As corrosion cells are changing within the structure, if chloride or moisture levels change then there will be a tendency for the system to demand more current.

Pile 21 exhibits an output current demand that initially increases with time, and then after about 6 months begins to drop, reaching the initial energizing level after 1 year.

\subsubsection{Dolphin 2- monitored control piles}

Pile 17 has the composite wrap and a bulk anode protecting the unwrapped portion of the pile. There was no wire mesh anode installed with the wrapped section, so the pile does not have a disconnectable anode. This design prevents the monitoring system from logging the anode output and carrying out depolarization tests. The instant-off potentials exhibited in Figure 23 indicate that $\mathrm{CP}$ is being provided to the unwrapped portion of the submerged pile section ( $\mathrm{R} 2$ and $\mathrm{R} 3$ ). $\mathrm{R} 1$ readings show that the wrapped portion has been protected randomly, which is possibly due to changing moisture levels in the concrete related to tide and wave action. Therefore, it cannot be assumed that a submerged anode alone can ensure the long-term durability of a pile. 


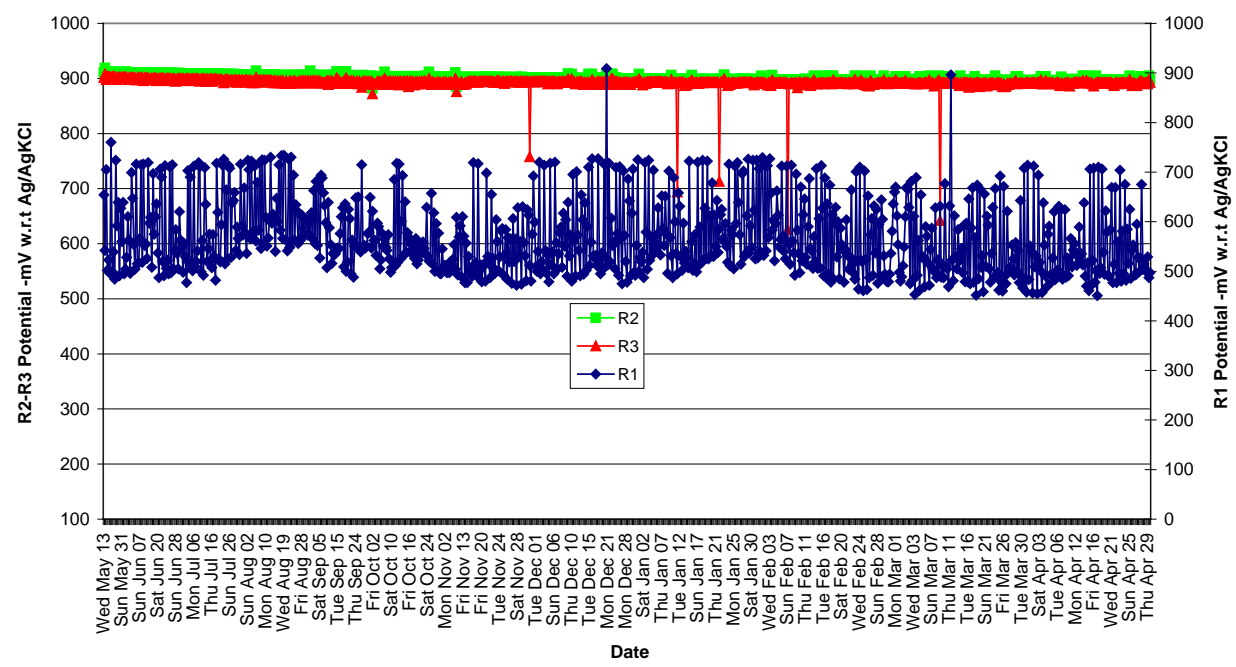

Figure 23. Instant-off potentials for first year, Dolphin 2, Pile 17 (wrap and bulk CP).

Pile 13 is wrapped but does not include any CP. Pile 15 had no wrap and no CP. During a site visit at the end of 2009 to establish remote access to the MCU and perform a firmware upgrade of the system, it was learned that the data for these piles were found to be in error. At that time, changes in the data-collection system were made to provide correct logging. The instant-off potentials from that point forward for both piles are shown in Figure 24 and Figure 25, respectively. It can be seen that no CP is being provided at any of the three reference electrodes for either pile.

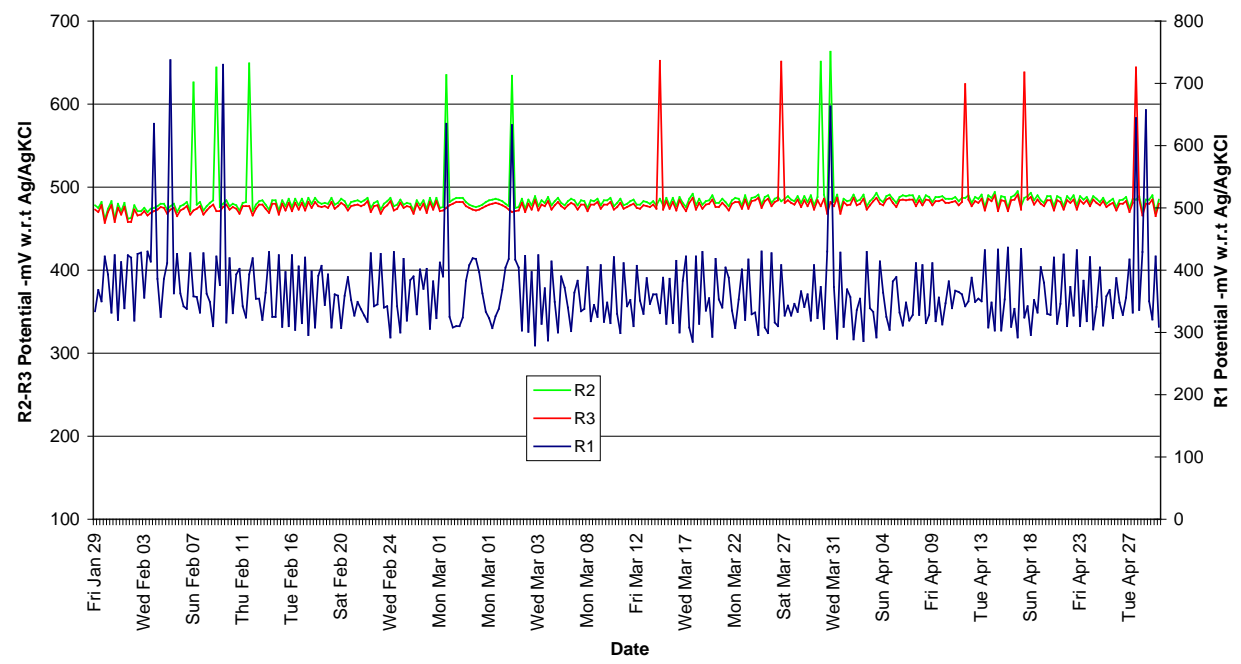

Figure 24. Instant-off potentials for first year, Dolphin 2, Pile 13 (wrap and no CP). 


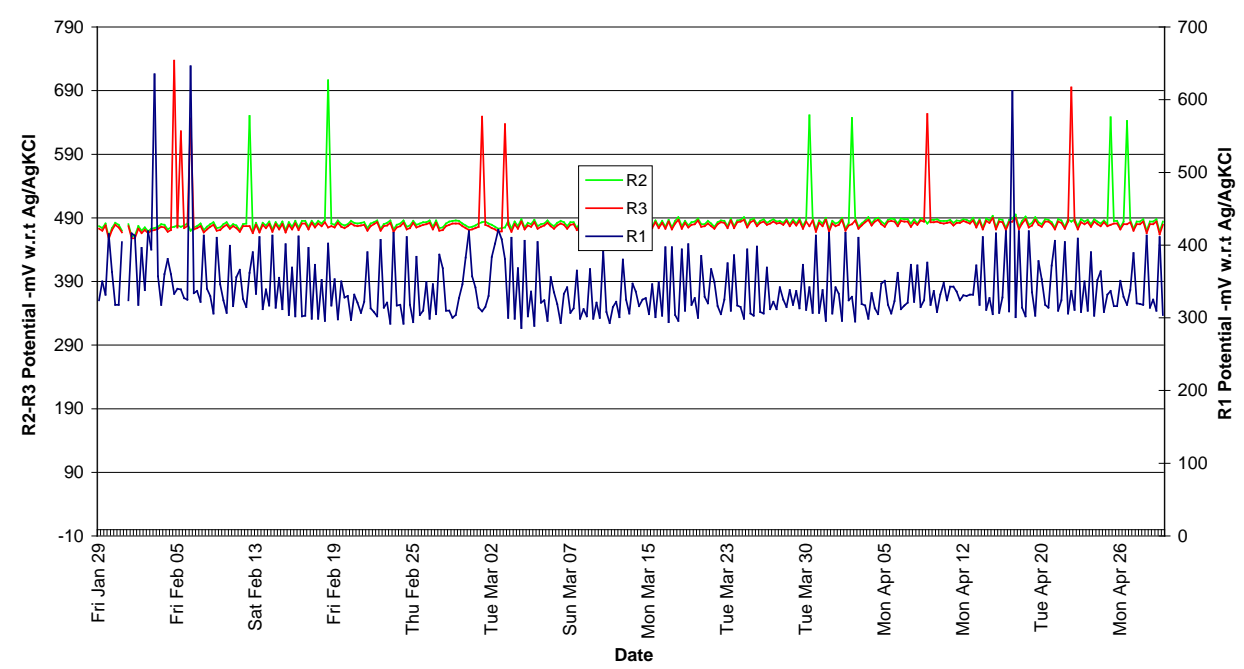

Figure 25. Instant-off potentials over first year, Dolphin 2, Pile 15 (no wrap or CP).

\subsubsection{Dolphin 3-monitored piles having full ICPW system}

Piles 2, 4, 12, and 18 of Dolphin 3 had the full ICPW system implemented. Figure 26, Figure 28, Figure 30 and Figure 32 show the instant-off potentials for the individual piles. As seen for Dolphin 2, the values for the reference electrodes (R1) placed under the composite wrap and above sea level vary more than the other two fully submerged reference electrodes (R2 and R3) that are protecting the unwrapped portion of the piles. This again, is likely due to the wetting and drying effects from the migration of moisture through the concrete.

The data also show that the $\mathrm{CP}$ criterion is being met intermittently within the wrapped section of the pile (R1) for three of the four piles. For Pile 12, the instant-off potentials are predominantly more negative than $-720 \mathrm{mV}$, indicating corrosion protection throughout the year. The readings for the reference electrodes R2 and R3 indicate corrosion protection for all four piles, with the reading for Pile 12 exhibiting an increase in fluctuation during the last 4 months.

The CP systems for all four ICPW piles show a reduction in output current demand (Figure 27, Figure 29, Figure 31, and Figure 33) from the initial energizing level until February 2010, when fluctuations in the readings became erratic. The cause of fluctuation is unknown, and a longer period of monitoring results will need to be assessed to understand the behavior. 


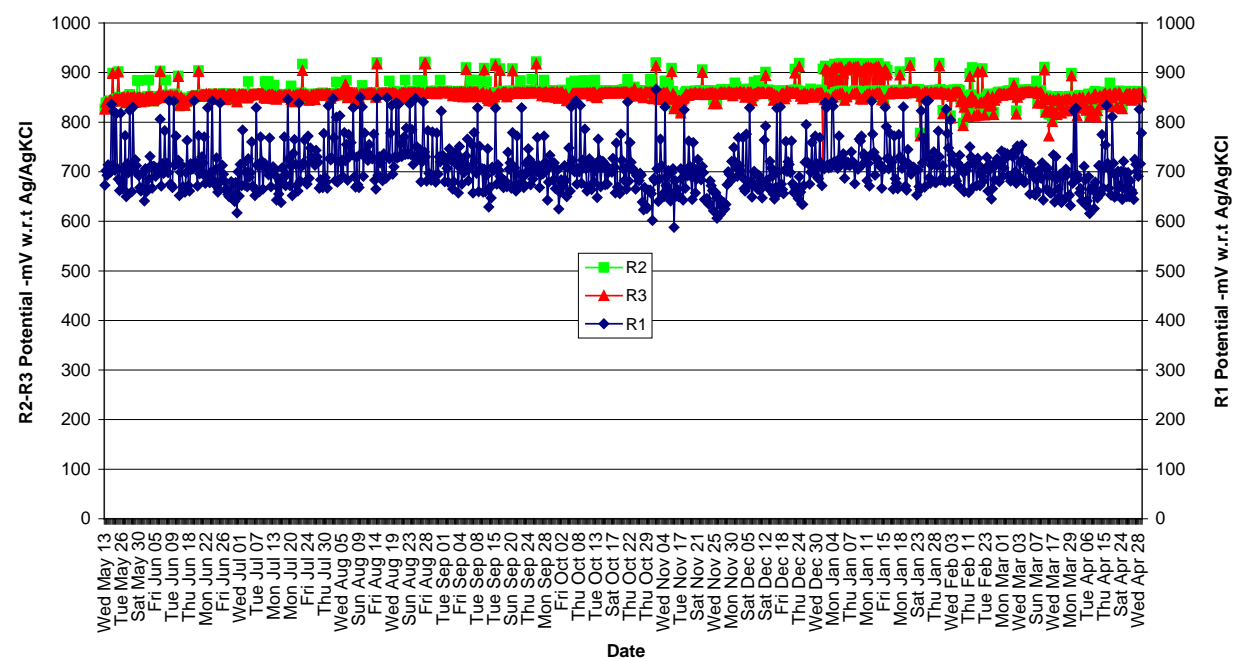

Figure 26. Instant-off potentials for first year, Dolphin 3, Pile 2 (full system).

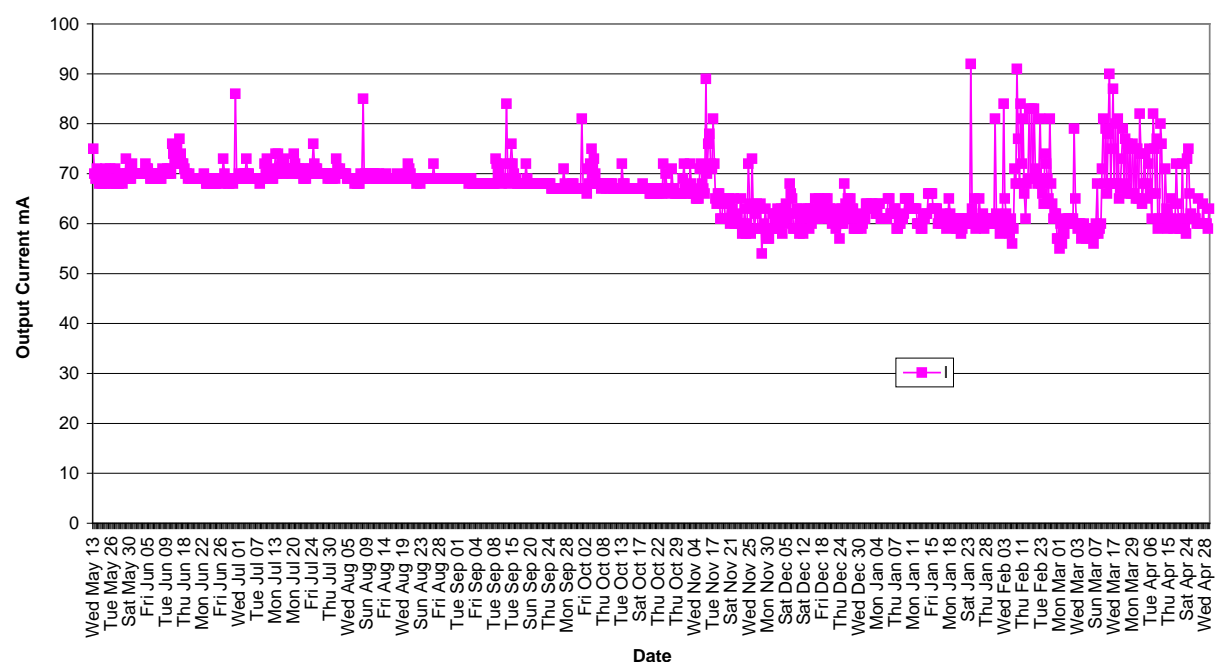

Figure 27. Output current for first year, Dolphin 3, Pile 2 (full system).

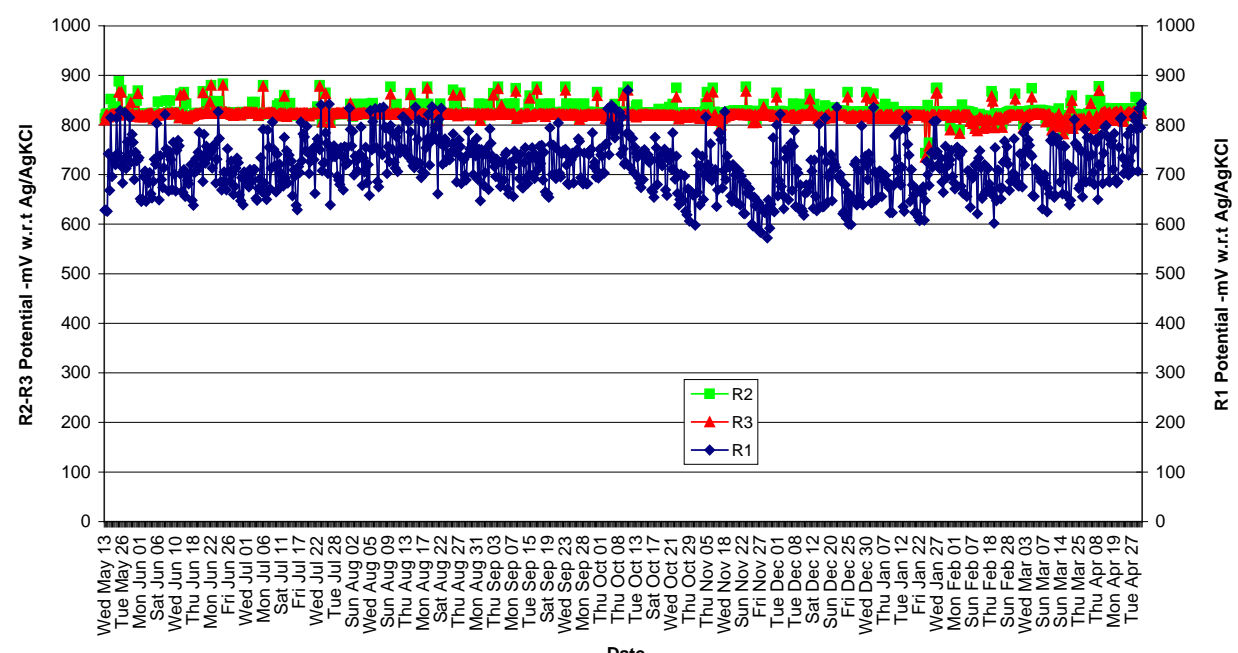

Figure 28. Instant-off potentials for first year, Dolphin 3, Pile 4 (full system). 


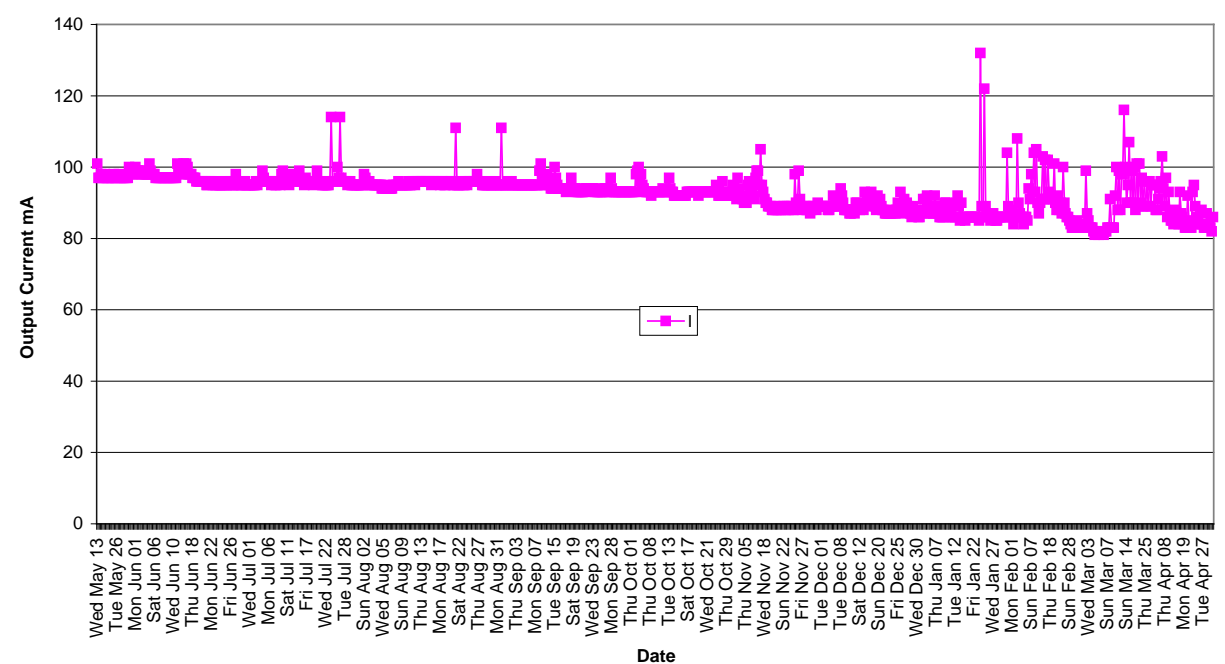

Figure 29. Output current for first year, Dolphin 3, Pile 4 (full system).

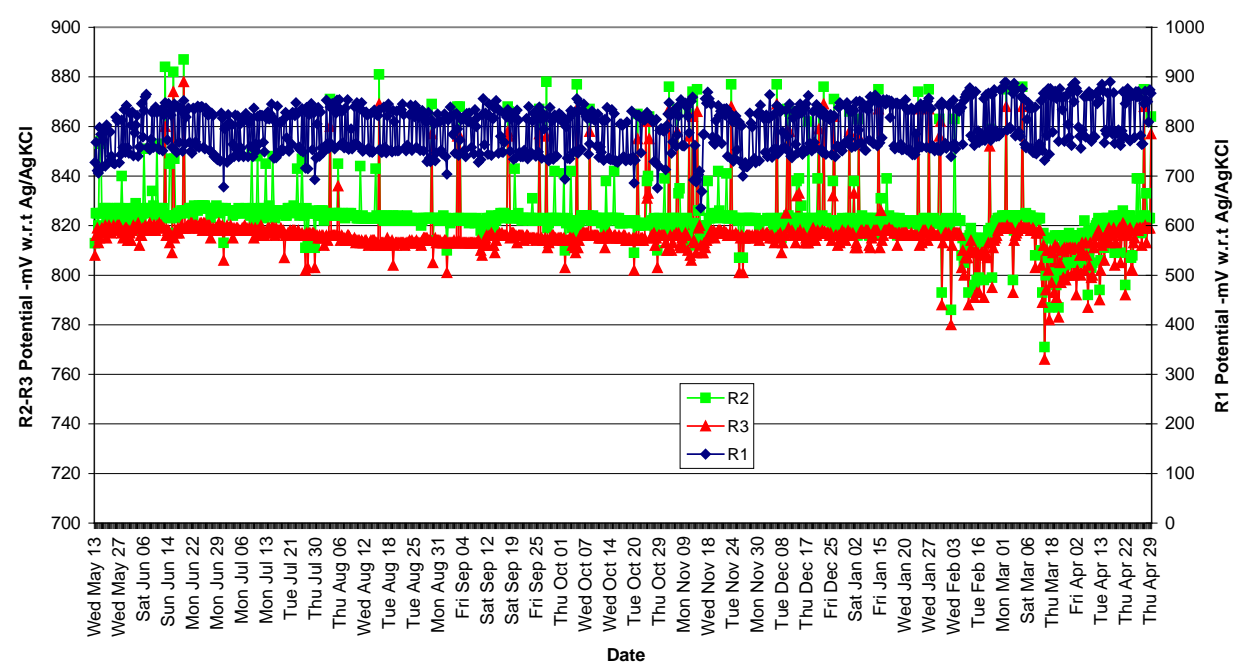

Figure 30. Instant-off potentials for first year, Dolphin 3, Pile 12 (full system).

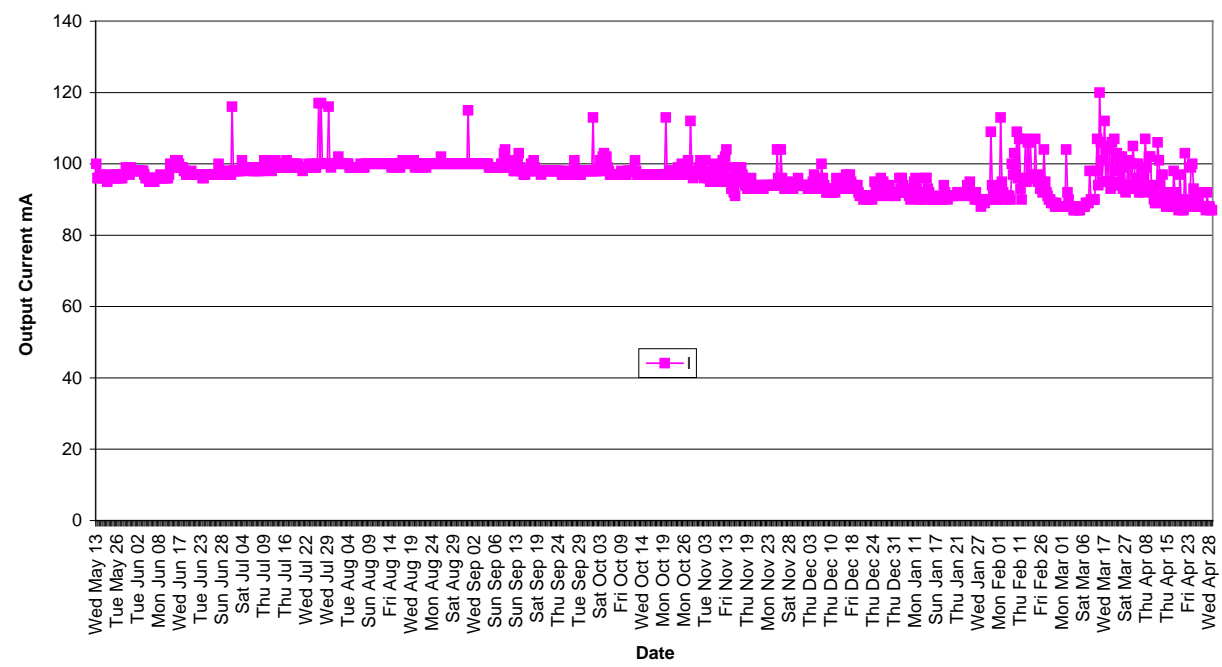

Figure 31. Output current for first year, Dolphin 3, Pile 12 (full system). 


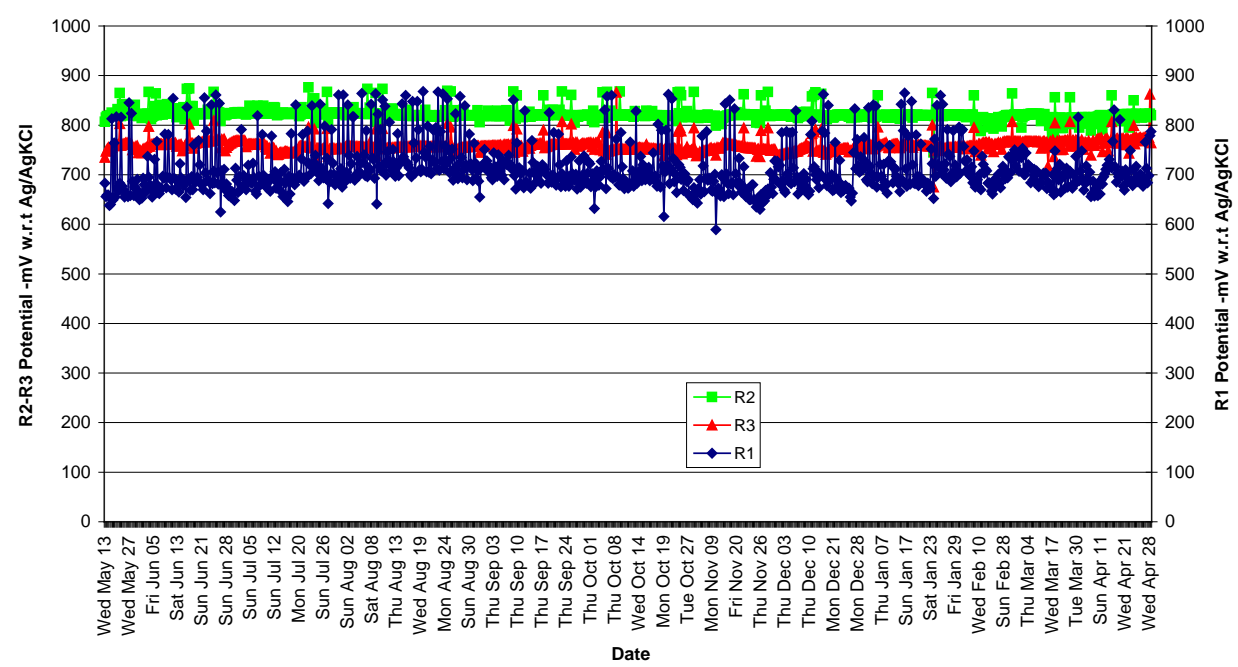

Figure 32. Instant-off potentials for first year, Dolphin 3, Pile 8 (full system).

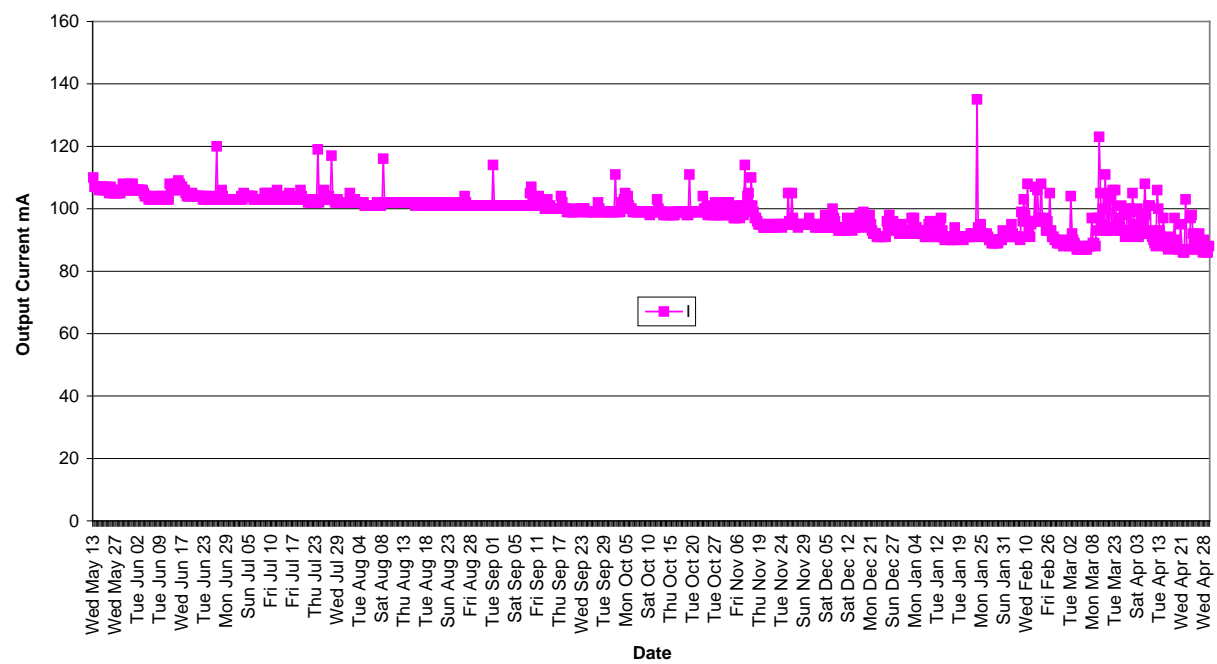

Figure 33. Output current for first year, Dolphin 3, Pile 8 (full system).

\subsubsection{Dolphin 3-monitored control piles}

Figure 34 shows the instant-off potentials for Pile 17, which has the composite wrap with no wire mesh anode but with the bulk anode. The data show that corrosion protection is being provided at the reference electrodes installed within the zone of protection established by the bulk anode system (R2 and R3). R1 has been protected randomly, which is possibly due to changing moisture levels in the concrete related to the tide and wave action. As with Dolphin 2, it cannot be assumed that a submerged anode alone will provide long-term protection for a pile.

Pile 14 had the composite wrap but no CP system, and Pile 16 had no wrap and no CP system. As was the case for Piles 13 and 15 of Dolphin 2, the in- 
stant-off potentials for these two piles were only recorded after late J anuary due to the same data-logging error. It can be seen in Figure 35 and Figure 36 that no $\mathrm{CP}$ is being provided to either pile at any of the three reference electrodes.

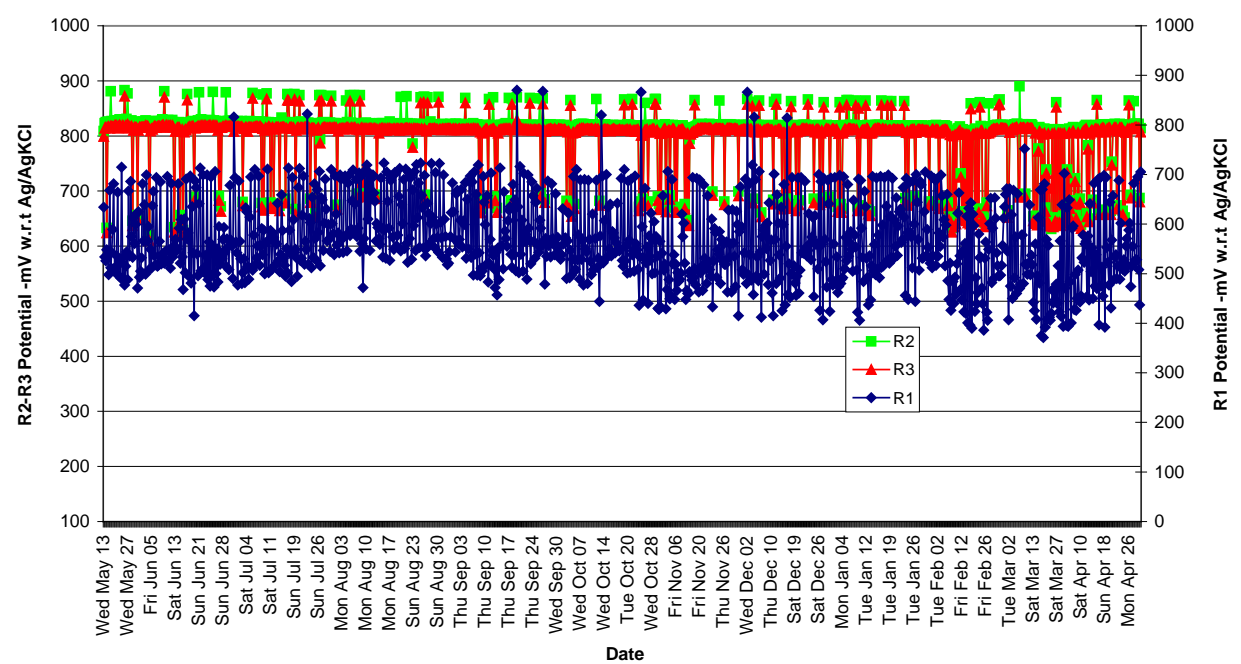

Figure 34 Instant-off potentials for first year, Dolphin 3, Pile 17 (wrap and bulk CP).

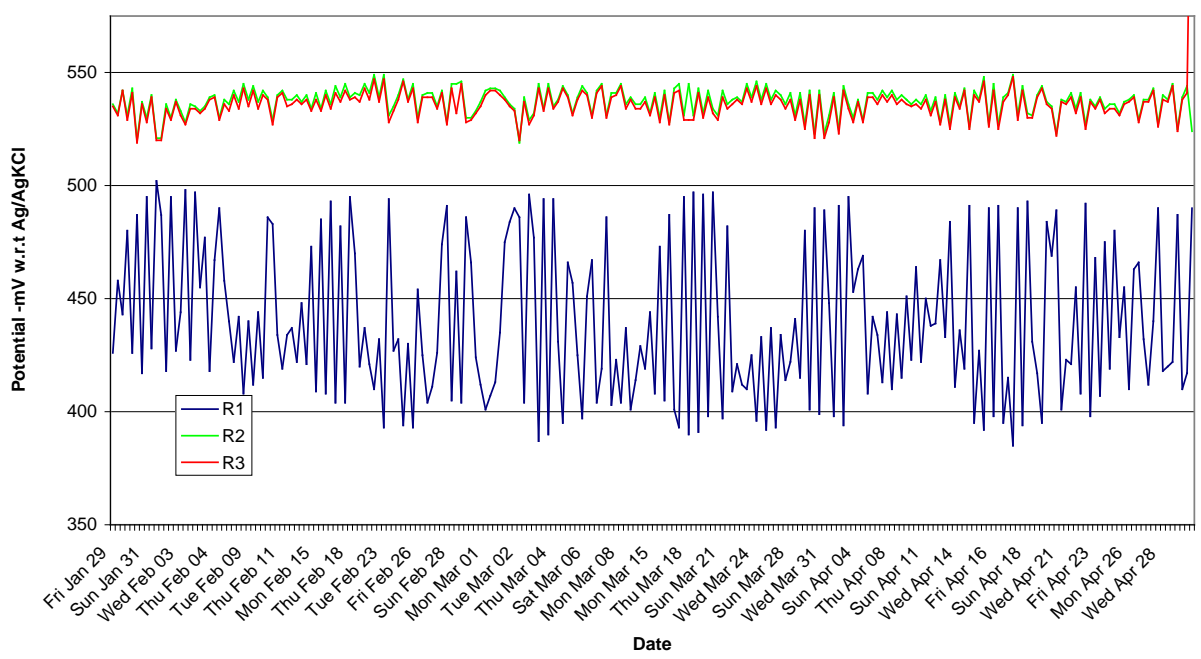

Figure 35. Instant-off potentials for first year, Dolphin 3, Pile 14 (wrap only). 


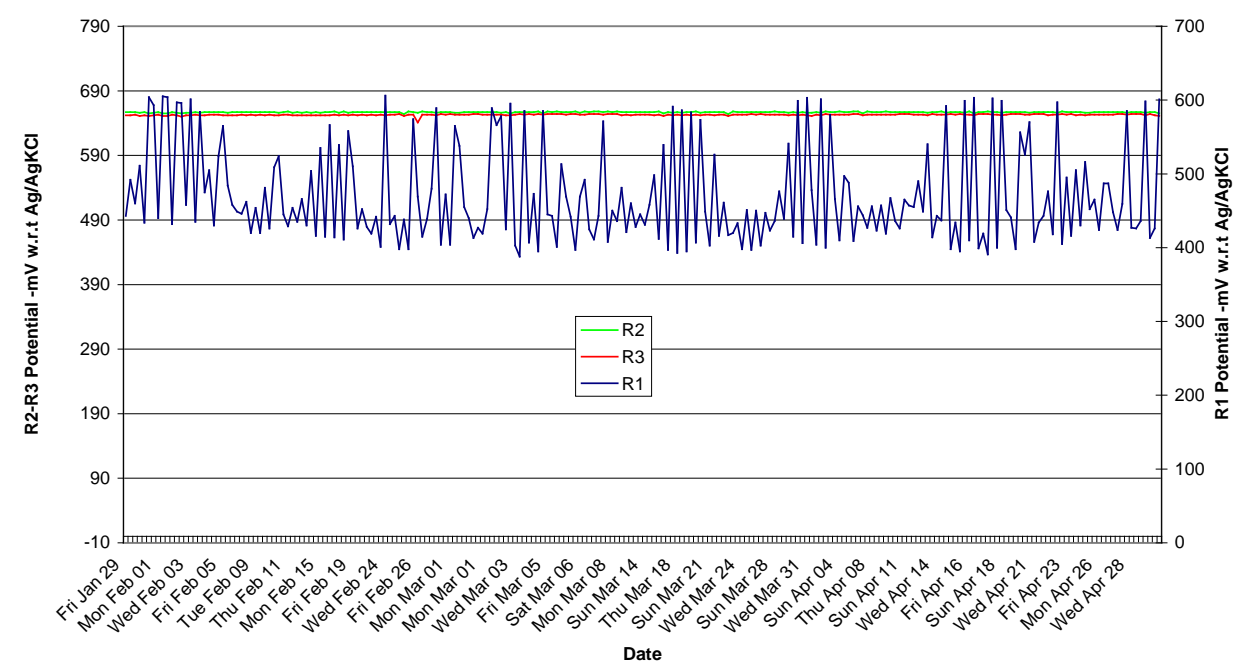

Figure 36. Instant-off potentials for first year, Dolphin 3, Pile 16 (no wrap or CP).

\subsection{Lessons learned}

During and after installation of the ICPW technology at Kawaihae Harbor, several lessons were learned related to the remote monitoring system.

\subsubsection{PV power}

Photovoltaic power was used to provide power for radio transmission of the data from the RMUs to the landside MCU and the monitoring of the system. Due to the restrictions on where the solar panel could be placed, several power outages have occurred at the site, resulting in interruption of data collection. As the power outages were typically less than 24 hours, only a minor amount of data was lost. For this demonstration, the solar panels needed to be installed on the face opposite of the docking side of the dolphin. It was decided that the panels should not be installed on the face with the access ladder because of vandalism concerns, or the opposite face because it had insufficient sun exposure. Attaching the panels to the docking face was not an option because the panels would be vulnerable to potential damage from the ships docking.

The use of solar panels in offshore locations appears to be viable, but selection of panel location must be carefully considered. From a system design perspective, a better understanding of the implications of solar panel location would be needed, particularly when constraints are imposed on the location of the solar panels. Consideration should be given to the number of usable solar exposure hours per day to maximize battery charging. Alternately, a dual battery system could be considered. 


\subsubsection{Data logging}

Two forms of data logging were employed in the demonstration-one solar-powered logger installed within the RMU on each dolphin and another within the landside MCU. Both recorded data every 6 hours.

The purpose of data logging at the RMU was to store data in the event that the wireless communication network becomes unreliable or disconnected. Within the RMU, data are recorded onto a memory card for removal and downloading on routine monitoring visits. This system feature has not provided any benefit as wireless communication with the MCU has been very reliable. Data logging within the MCU has performed exceptionally well and has provided uninterrupted communications at all time. It has produced an enormous amount of data, and was affected only by power outages at the solar panel. The data logging within the MCU has proven to be the more effective of the two methods due to the ease of access and the availability of this stored data through the Internet.

A number of modifications were made to the wireless radios by moving the remote aerials at the RMUs to positions with a line of sight to the landbased MCU. This has provided a flawless connection to the dolphins, allowing the system to fully operate and remotely control the system.

\subsubsection{MCU and Internet access}

The MCU is an industrial computer that provides remote access to users via the Internet. It runs dedicated software that provides live and logged data. The unit is powered by a local alternating current (AC) supply, which for the past year has been $100 \%$ reliable. As this project is located a long distance from the continental United States, the benefits of having this type of system are considerable.

The one setback for this system was the DoD-mandatory computer security settings, which did not allow for the software to be installed. To provide live data from the MCU, a series of ports allowing data transfer is required to be open within the firewall of DoD computer systems. The opening of the necessary ports has been denied. However, ERDC-CERL is investigating other alternatives to resolve the accessibility issue. 


\section{Economic Summary}

The costs of repairing and rebuilding marine structures such as dolphins and landing platforms that are supported with reinforced concrete piles depend on several variables. These include site access, submerged subgrade conditions, and tidal conditions. The condition of the piles must also be considered. In addition to these variables, differences in the design of these structures will also affect any calculation of cost savings. This economic summary and return on investment (ROI) calculation pertains specifically to the Kawaihae Harbor demonstration project.

\subsection{Costs and assumptions}

The total cost for implementing the technology on the project piles at Kawaihae Harbor was $\$ 664 \mathrm{~K}$. The remaining project funds were expended for CPC project management and performance monitoring. A breakdown of implementation costs is shown below:

- design and engineering

$\$ 19 \mathrm{~K}$

- composite wrap and CP installation

$\$ 477 \mathrm{~K}$

- reference electrode installation

$\$ 37 \mathrm{~K}$

- wiring, conduit, data transfer

$\$ 131 K$

The estimated total cost for applying the ICPW system to all of the remaining unwrapped piles supporting the two dolphin piers is $\$ 480 \mathrm{~K}$. Based on the design life of the individual components and projections from laboratory and field applications, the proposed polymeric composite wrap and integrated CP system will have a maintenance-free life of 20 years. Even when the ICPW begins to fail, the dolphin structure and piles will continue to provide service with an expected annual maintenance cost of $\$ 10 \mathrm{~K}$ per year. With the additional protection, a pier's total expected service life is 30 years. With the increased durability provided by the polymeric composite wrap and CP system, the piles would need to be inspected every 5 years. Installation of the pile wrap and CP system is assumed to avert a \$2 million impact (facility downtime and loss of training mission during repair effort) to the existing harbor complex after 15 years of service life (Year 5). 
At Year 1 of the ROI analysis, the existing piers were 10 years old. At this point, an estimated $\$ 60 \mathrm{~K}$ per year is needed for repair of concrete spalling and cracks and pile strengthening required because of damage from corrosion and impact. It is expected that the structure would need to be replaced after a total of 20 years of service, based on the actual service life of the previous dolphin pier structures at the site. Replacement would cost an estimated $\$ 4.5$ million. This estimate was obtained from the general contractor that built the existing structures. If the piles were to remain unprotected, they would need to be inspected every year. An annual cost of $\$ 1,350$ for this work is assumed over 30 years.

For this analysis, a second set of piers at another Army docking facility is assumed. The piers are 5 years old and have the same construction, provide similar performance, and have the same maintenance requirements as the dolphin piers at Kawaihae Harbor. The ICPW system will be implemented on the facility after 10 years of service life.

\subsection{Projected return on investment (ROI)}

As specified in Office of Management and Budget (OMB) Circular No. A94, a life-cycle cost (LCC) analysis was performed using a 30 year real discount rate of $7.00 \%$. The resulting ROI calculation is summarized in Table 3. Implementation of the ICPW system on the two dolphin piers at Kawaihae Harbor and another Army facility would provide an ROI of 4.44. Details of the analysis can be seen in Table 4.

The major assumption in this ROI analysis is that the primary mode of cost savings for the installation of the ICPW is reduction of maintenance, repair, and inspection costs, avoidance of facility downtime and postponement of replacement costs. 
Table 3. Return on investment calculation.

\begin{tabular}{|c|c|c|c|c|c|c|c|}
\hline & & & Investr & nent Required & & & $1,092,000$ \\
\hline & & & Return on Inv & estment Ratio & 4.44 & Percent [ & $444 \%$ \\
\hline & Net $P$ & resent Value of & Costs and $\mathrm{Be}$ & nefits/Savings & $3,572,306$ & $8,417,561$ & $4,845,255$ \\
\hline $\begin{array}{l}\text { A } \\
\text { Future } \\
\text { Year }\end{array}$ & $\begin{array}{c}\text { B } \\
\text { Baseline Costs }\end{array}$ & $\begin{array}{c}\text { C } \\
\text { Baseline } \\
\text { Benefits/Savings }\end{array}$ & $\begin{array}{l}\text { D } \\
\text { New System } \\
\text { Costs }\end{array}$ & $\begin{array}{c}\text { E } \\
\text { New System } \\
\text { Benefits/Savings }\end{array}$ & $\begin{array}{c}F \\
\text { Present Value of } \\
\text { Costs }\end{array}$ & $\begin{array}{l}\text { G } \\
\text { Present Value of } \\
\text { Savings }\end{array}$ & $\begin{array}{c}\mathbf{H} \\
\text { Total Present } \\
\text { Value }\end{array}$ \\
\hline 1 & 61,350 & & 480,000 & & 448,608 & 57,338 & $-391,270$ \\
\hline 2 & 61,350 & & & & & 53,583 & 53,583 \\
\hline 3 & 61,350 & & & & & 50,080 & 50,080 \\
\hline 4 & 61,350 & & & & & 46,804 & 46,804 \\
\hline 5 & 61,350 & & & $2,000,000$ & & $1,469,743$ & $1,469,743$ \\
\hline 6 & 122,700 & & 960,000 & & 639,648 & 81,755 & $-557,893$ \\
\hline 7 & 122,700 & & & & & 76,405 & 76,405 \\
\hline 8 & 122,700 & & & & & 71,411 & 71,411 \\
\hline 9 & 122,700 & & & & & 66,737 & 66,737 \\
\hline 10 & $4,561,350$ & & 11,350 & $2,000,000$ & 5,769 & $3,335,134$ & $3,329,365$ \\
\hline 11 & 61,350 & & 10,000 & & 4,751 & 29,147 & 24,396 \\
\hline 12 & 61,350 & & 10,000 & & 4,440 & 27,239 & 22,799 \\
\hline 13 & 61,350 & & 10,000 & & 4,150 & 25,460 & 21,310 \\
\hline 14 & 61,350 & & 10,000 & & 3,878 & 23,792 & 19,914 \\
\hline 15 & $4,500,000$ & & 22,700 & & 8,226 & $1,630,800$ & $1,622,574$ \\
\hline 16 & & & 20,000 & & 6,774 & & $-6,774$ \\
\hline 17 & & & 20,000 & & 6,332 & & $-6,332$ \\
\hline 18 & & & 20,000 & & 5,918 & & $-5,918$ \\
\hline 19 & & & 20,000 & & 5,530 & & $-5,530$ \\
\hline 20 & & & $5,471,350$ & & $1,413,797$ & & $-1,413,797$ \\
\hline 21 & 61,350 & & 10,000 & & 2,415 & 14,816 & 12,401 \\
\hline 22 & 61,350 & & 10,000 & & 2,257 & 13,847 & 11,590 \\
\hline 23 & 61,350 & & 10,000 & & 2,109 & 12,939 & 10,830 \\
\hline 24 & 61,350 & & 10,000 & & 1,971 & 12,092 & 10,121 \\
\hline 25 & 61,350 & & $5,460,000$ & $2,000,000$ & $1,005,732$ & \begin{tabular}{|l|l|}
379,701 \\
\end{tabular} & $-626,031$ \\
\hline 26 & 122,700 & & & & & 21,129 & 21,129 \\
\hline 27 & 122,700 & & & & & 19,742 & 19,742 \\
\hline 28 & 122,700 & & & & & 18,454 & 18,454 \\
\hline 29 & 122,700 & & & & & 17,252 & 17,252 \\
\hline 30 & $4,561,350$ & & & $2,000,000$ & & 862,161 & 862,161 \\
\hline
\end{tabular}


Table 4. Yearly costs and benefits for baseline and new technology scenarios.

\begin{tabular}{|c|c|c|c|c|c|c|c|c|c|c|c|c|c|c|c|c|c|c|c|c|c|c|}
\hline \multirow[b]{2}{*}{$\mathrm{Yr}$} & \multirow{2}{*}{\multicolumn{5}{|c|}{$\begin{array}{l}\text { Kawaihae Piers - Baseline } \\
\text { nals }\end{array}$}} & \multicolumn{5}{|c|}{ 2nd Facility - Baseline } & \multirow[t]{2}{*}{ Total } & \multicolumn{4}{|c|}{ Kawaihae - New Technology } & \multirow{2}{*}{\multicolumn{4}{|c|}{ 2nd Facility - New Technology }} & \multirow[t]{2}{*}{ Total } & \multirow{2}{*}{$\begin{array}{c}\text { Yearly } \\
\text { Savings } \\
\end{array}$} & \multirow{2}{*}{ Net Savings } \\
\hline & & & & & Impact Cost & age & Replace If & Inspection & Maint. & Impact Cost & & Age & Implement & Inspect & Maint. & & & & Maint. & & & \\
\hline 1 & 11 & & $\$ 1,350$ & $\$ 60,000$ & & 6 & & & & & $\$ 61,350$ & 11 & $\$ 1,572,000$ & & & 6 & & & & $\$ 1,572,000$ & $-\$ 1,510,650$ & $-\$ 1,510,650$ \\
\hline 2 & 12 & & $\$ 1,350$ & $\$ 60,000$ & & 7 & & & & & $\$ 61,350$ & 12 & & & & 7 & & & & $\$ 0$ & $\$ 61,350$ & $-\$ 1,449,300$ \\
\hline 3 & 13 & & $\$ 1,350$ & $\$ 60,000$ & & 8 & & & & & $\$ 61,350$ & 13 & & & & 8 & & & & $\$ 0$ & $\$ 61,350$ & $-\$ 1,387,950$ \\
\hline 4 & 14 & & $\$ 1,350$ & $\$ 60,000$ & & 9 & & & & & $\$ 61,350$ & 14 & & & & 9 & & & & $\$ 0$ & $\$ 61,350$ & $-\$ 1,326,600$ \\
\hline 5 & 15 & & $\$ 1,350$ & $\$ 60,000$ & $\$ 2,000,000$ & 10 & & & & & $\$ 2,061,350$ & 15 & & & & 10 & & & & $\$ 0$ & $\$ 2,061,350$ & $\$ 734,750$ \\
\hline 6 & 16 & & $\$ 1,350$ & $\$ 60,000$ & & 11 & & $\$ 1,350$ & $\$ 60,000$ & & $\$ \$ 122,700 \mid$ & 16 & & & & 11 & $\$ 960,000$ & & & $\$ 960,000$ & $-\$ 837,300$ & $-\$ 102,550$ \\
\hline 7 & 17 & & $\$ 1,350$ & $\$ 60,000$ & & 12 & & $\$ 1,350$ & $\$ 60,000$ & & $\$ 122,700$ & 17 & & & & 12 & & & & $\$ 0$ & $\$ 122,700$ & $\$ 20,150$ \\
\hline 8 & 18 & & $\$ 1,350$ & $\$ 60,000$ & & 13 & & $\$ 1,350$ & $\$ 60,000$ & & $\$ 122,700$ & 18 & & & & 13 & & & & $\$ 0$ & $\$ 122,700$ & $\$ 142,850$ \\
\hline 9 & 19 & & $\$ 1,350$ & $\$ 60,000$ & & 14 & & $\$ 1,350$ & $\$ 60,000$ & & $\$ 122,700$ & \begin{tabular}{|c|}
19 \\
\end{tabular} & & & & 14 & & & & $\$ 0$ & $\$ 122,700$ & $\$ 265,550$ \\
\hline 10 & 20 & $\$ 4,500,000$ & & & & 15 & & $\$ 1,350$ & $\$ 60,000$ & $\$ 2,000,000$ & $\$ 6,561,350$ & 20 & & $\$ 1,350$ & $\$ 10,000$ & 15 & & & & $\$ 11,350$ & $\$ 6,550,000$ & $\$ 6,815,550$ \\
\hline 11 & 1 & & & & & 16 & & $\$ 1,350$ & $\$ 60,000$ & & $\$ 61,350$ & 21 & & & $\$ 10,000$ & \begin{tabular}{|l|}
16 \\
\end{tabular} & & & & $\$ 10,000$ & $\$ 51,350$ & $\$ 6,866,900$ \\
\hline 12 & 2 & & & & & 17 & & $\$ 1,350$ & $\$ 60,000$ & & $\$ 61,350$ & 22 & & & $\$ 10,000$ & \begin{tabular}{|l|l}
17 \\
\end{tabular} & & & & $\$ 10,000$ & $\$ 51,350$ & $\$ 6,918,250$ \\
\hline 13 & 3 & & & & & 18 & & $\$ 1,350$ & $\$ 60,000$ & & $\$ 61,350$ & 23 & & & $\$ 10,000$ & \begin{tabular}{|l|}
18 \\
\end{tabular} & & & & $\$ 10,000$ & $\$ 51,350$ & $\$ 6,969,600$ \\
\hline 14 & 4 & & & & & 19 & & $\$ 1,350$ & $\$ 60,000$ & & $\$ 61,350$ & 24 & & & $\$ 10,000$ & 19 & & & & $\$ 10,000$ & $\$ 51,350$ & $\$ 7,020,950$ \\
\hline 15 & 5 & & & & & 20 & $\$ 4,500,000$ & & & & $\$ 4,500,000$ & 25 & & $\$ 1,350$ & $\$ 10,000$ & 20 & & $\$ 1,350$ & $\$ 10,000$ & $\$ 22,700$ & $\$ 4,477,300$ & $\$ 11,498,250$ \\
\hline 16 & 6 & & & & & 1 & & & & & $\$ 0$ & 26 & & & $\$ 10,000$ & 21 & & & $\$ 10,000$ & $\$ 20,000$ & $-\$ 20,000$ & $\$ 11,478,250$ \\
\hline 17 & 7 & & & & & 2 & & & & & $\$ 0$ & 27 & & & $\$ 10,000$ & 22 & & & $\$ 10,000$ & $\$ 20,000$ & $-\$ 20,000$ & $\$ 11,458,250$ \\
\hline 18 & 8 & & & & & 3 & & & & & $\$ 0$ & 28 & & & $\$ 10,000$ & 23 & & & $\$ 10,000$ & $\$ 20,000$ & $-\$ 20,000$ & $\$ 11,438,250$ \\
\hline 19 & 9 & & & & & 4 & & & & & $\$ 0$ & 29 & & & $\$ 10,000$ & 24 & & & $\$ 10,000$ & $\$ 20,000$ & $-\$ 20,000$ & $\$ 11,418,250$ \\
\hline 20 & 10 & & & & & 5 & & & & & $\$ 0$ & 30 & $\$ 5,460,000$ & & & 25 & & $\$ 1,350$ & $\$ 10,000$ & $\$ 5,471,350$ & $-\$ 5,471,350$ & $\$ 5,946,900$ \\
\hline 21 & 11 & & $\$ 1,350$ & $\$ 60,000$ & & 6 & & & & & $\$ 61,350$ & 1 & & & & 26 & & & $\$ 10,000$ & $\$ 10,000$ & $\$ 51,350$ & $\$ 5,998,250$ \\
\hline 22 & 12 & & $\$ 1,350$ & $\$ 60,000$ & & 7 & & & & & $\$ 61,350$ & 2 & & & & \begin{tabular}{|l|}
27 \\
\end{tabular} & & & $\$ 10,000$ & $\$ 10,000$ & $\$ 51,350$ & $\$ 6,049,600$ \\
\hline 23 & 13 & & $\$ 1,350$ & $\$ 60,000$ & & 8 & & & & & $\$ 61,350$ & 3 & & & & 28 & & & $\$ 10,000$ & $\$ 10,000$ & $\$ 51,350$ & $\$ 6,100,950$ \\
\hline 24 & 14 & & $\$ 1,350$ & $\$ 60,000$ & & 9 & & & & & $\$ 61,350$ & 4 & & & & 29 & & & $\$ 10,000$ & $\$ 10,000$ & $\$ 51,350$ & $\$ 6,152,300$ \\
\hline 25 & 15 & & $\$ 1,350$ & $\$ 60,000$ & $\$ 2,000,000$ & 10 & & & & & $\$ 2,061,350$ & 5 & & & & 30 & $\$ 5,460,000$ & & & $\$ 5,460,000$ & $-\$ 3,398,650$ & $\$ 2,753,650$ \\
\hline 26 & 16 & & $\$ 1,350$ & $\$ 60,000$ & & 11 & & $\$ 1,350$ & $\$ 60,000$ & & $\$ 122,700$ & 6 & & & & 1 & & & & $\$ 0$ & $\$ 122,700$ & $\$ 2,876,350$ \\
\hline 27 & 17 & & $\$ 1,350$ & $\$ 60,000$ & & 12 & & $\$ 1,350$ & $\$ 60,000$ & & $\$ 122,700$ & 7 & & & & 2 & & & & $\$ 0$ & $\$ 122,700$ & $\$ 2,999,050$ \\
\hline 28 & 18 & & $\$ 1,350$ & $\$ 60,000$ & & 13 & & $\$ 1,350$ & $\$ 60,000$ & & $\$ 122,700$ & 8 & & & & 3 & & & & $\$ 0$ & $\$ 122,700$ & $\$ 3,121,750$ \\
\hline 29 & 19 & & $\$ 1,350$ & $\$ 60,000$ & & 14 & & $\$ 1,350$ & $\$ 60,000$ & & $\$ 122,700$ & 9 & & & & 4 & & & & $\$ 0$ & $\$ 122,700$ & $\$ 3,244,450$ \\
\hline \multirow[t]{9}{*}{30} & 20 & $\$ 4,500,000$ & & & & 15 & & $\$ 1,350$ & $\$ 60,000$ & $\$ 2,000,000$ & $|\$ 6,561,350|$ & 10 & & & & 5 & & & & $\$ 0$ & $\$ 6,561,350$ & $\$ 9,805,800$ \\
\hline & & & & & & & & & & & & & & & & & & & & & & \\
\hline & & & & & & & $\$ 480,000$ & & Costford & foing ICPW o & remaining & Kawaih _ & pe piles & & & & & & & & & \\
\hline & & & & & & & $\$ 960,000$ & & Cost ford & Joing similar t. & two piers at ar & nother & site & & & & & & & & & \\
\hline & & & & & & & $\$ 1,350$ & & Cost for a & annual inspec & tion for piers & at eac & h site & & & & & & & & & \\
\hline & & & & & & & $\$ 60,000$ & & Annual sit & te costs for re & pairs on conv & vention & nal piers after & 10 years & & & & & & & & \\
\hline & & & & & & & $\$ 10,000$ & & Annual sit & te costs for re & pairs on ICPI & W pier & $s$ after 20 year & & & & & & & & & \\
\hline & & & & & & & $\$ 4,500,000$ & & Replacem & ment cost for & peirs at one si & & & & & & & & & & & \\
\hline & & & & & & & $\$ 2,000,000$ & & Cost of im & npact averted & after 15 years & of ser & vice of conven & intional pie & & & & & & & & \\
\hline
\end{tabular}




\section{Conclusions and Recommendations}

\subsection{Conclusions}

Steel-reinforced concrete marine piles are damaged by the impact of floating debris, general deterioration, spalling of the concrete, and corrosion of the steel reinforcement. This study has determined that a fiber-reinforced polymer composite wrap with an integrated cathodic protection system, designed and installed using commercially available products, can protect and extend the life of such piles.

A contractor was selected to design, fabricate, assemble, and install an innovative pile wrapping system intended for use in protecting piles from impact damage in the splash zone. The wrapping system incorporates a CP system that includes a wire mesh galvanic anode that protects steel in the wrapped portion of the pile and a bulk anode that protects steel in the unwrapped, submerged portion of the pile. The CP system also includes a corrosion monitoring and data logging capability. The impact and corrosion protection wrap (ICPW) system was installed on 10 piles supporting each of two dolphin piers at Kawaihae Harbor. Installation required a dive crew and a CP installation crew.

The installed corrosion monitoring system, which uses silver/ silver chloride reference electrodes, has shown that the $\mathrm{CP}$ system performs in accordance with NACE SP0169-2007. Data logged from the corrosion monitoring the dolphins has enabled us to evaluate how effective the system has been.

The demonstration piles on which the full ICPW system was installed are protected from corrosion at both their wrapped and unwrapped sections.

For the control piles with the composite wrap and bulk anode, but without the mesh anode beneath the wrapping system, data indicate that corrosion protection is being provided at the submerged and unwrapped portion of the pile, but not to the steel within the wrapped section. Corrosion-related failure of these control piles would be expected within 10 years, making repairs necessary in order to avoid loss of capability. For these same piles, it is also concluded that corrosion damage to the reinforcing steel will lead to damage of the composite wrap within the tidal splash zone. The wrap 
will potentially slow down the corrosion process in comparison to piles without wrapping or CP.

Monitoring of the control piles with no CP shows corrosion proceeding as would be expected. Reference potentials indicate that the steel is actively corroding, which will lead to degradation of the concrete and the need for repairs. Corrosion-related failure of unprotected piles would be expected within 15 years.

\subsection{Recommendations}

\subsubsection{Applicability}

It is recommended that the demonstrated ICPW system, which combines composite wrap technology with galvanic cathodic protection, be applied to in-service marine piles that have a life extension requirement.

The demonstrated ICPW system can be used in a retrofit application, and also potentially for newly constructed facilities, to provide (1) structural reinforcement to the concrete, (2) impact and abrasion protection, (3) corrosion prevention and control, and (4) reduction of maintenance needs. Using a dive crew, the system can be installed in a submerged or splash zone to eliminate the need for dewatering the work area. A low-cost data logger can be used to remotely monitor the project through a standard Internet connection.

In addition, this technology application should be considered for structures that cannot be frequently taken out of service for routine repairs due to operational requirements or mission criticality. The ICPW system is designed to reduce costs and disruption of operations over the whole facility life cycle.

\subsubsection{Implementation}

The ICPW technology should be integrated into existing criteria documents that address the maintenance and repair of marine structures. These include:

- Unified Facilities Criteria (UFC) 4-150-07, "Maintenance and Operation: Maintenance of Waterfront Facilities" 
- Unified Facilities Guide Specification (UFGS) 03 0132, “Concrete Rehabilitation for Civil Works"

- Technical Manual (TM) 5-622, "Maintenance of Waterfront Facilities."

The UFGS 2642 14, "Cathodic Protection System (Sacrificial Anode)," also should be revised to incorporate the $\mathrm{CP}$ aspects of the ICPW technology. 


\section{References}

Broomfield, J ohn. 1997. Corrosion of Steel in Concrete: Understanding, Investigation and Repair. London: E \& FN Spon.

LMI. May 2007. The Annual Cost of Corrosion for the Department of Defense Facilities and Infrastructure.

NACE Recommended Practice RP0187-2005, “Design Considerations For Corrosion Control of Reinforcing Steel in Concrete." Houston, TX: NACE International.

NACE Standard Practice SP0290-2007. "Cathodic Protection of Steel in Atmospherically Exposed Concrete Structures.” Houston, TX: NACE International.

NACE Standard Practice SP0169-2007. "Control of External Corrosion on Underground or Submerged Metallic Piping." Houston, TX: NACE International.

Sen, R., and G. Mullins. 2007. “Application of FRP Composites for Underwater Piles Repair,” Composites, Part b 38 (751- 758).

Tehada, T., and R. J amond. April 2008. Integrated Concrete Pier Piling Repair and Corrosion Protection System. Corrosion Prevention and Control Program Final Report FY05 OSD Project N-F-229. Port Hueneme, CA: Naval Facilities Engineering Service Center.

Verhulst, S., L. A. Fuentes, J . O. J irsa, D. W. Fowler, H. G. Wheat, and T. Moon. J anuary 2001. Evaluation and Performance Monitoring of Corrosion Protection of FiberReinforced CompositeWrapping. Research Report 1774-1. Austin, TX:

University of Texas. 


\section{Appendix: CP System Design Calculations}

\section{Steel surface area calculations}

The cathodic protection system provides protective current to the embedded reinforcing steel. Calculations are provided to ascertain the current density of the system based on the amount steel divided by the amount of output current. This enables us to calculate and determine the life expectancy from the system.

The following calculations are based on information retrieved from the original construction drawings. For calculation purposes, we need to determine the entire surface area of all reinforcing steel used in each pile. This will require determining the exposed surface area of the vertical steel reinforcing tendons and the exposed surface area of the spiral tie that connects and supports these tendons. For ease of future calculations, we will determine the total surface area of the reinforcing steel per lineal foot of pile.

The original drawings indicate the reinforcement within the piles is coated with epoxy. However, our field visits reveal leftover piles that do not have coating over the tendons. The presence of a coating cannot be confirmed without destructive tests. As such, a conservative approach will be followed and we will assume there is no coating on the steel.

For each pile the vertical steel reinforcement consists of seven each $1 / 2$ in. diameter tendons consisting of seven wire strands. For the purpose of this calculation each tendon will be assumed to be solid. The spiral tie is $3 \mathrm{GA}$. ( $0.2437 \mathrm{in}$. dia.) of varying pitch (assumed at 3 in.) on a diameter of 10.5 in. (obtained from drawings). To calculate the total surface area of the spiral tie, we will assume that there are 4 circular (10.5 in. diameter) ties per foot of pile.

The total area of steel per linear foot of pile is thus:

\section{Surface area of reinforcing steel per $\mathrm{ft}$ of pile $=\mathrm{A}+\mathrm{B}$}

$\mathrm{A}=$ Surface area of the spiral tie $=$ surface area of the $3 \mathrm{GA}$ (0.2437 dia) wire ( $\mathrm{Pi} x$ 0.2437) $\mathrm{x}$ length of wire (Pi x 10.5) $\mathrm{x} 4$ spirals/ $\mathrm{ft}$ of pile. 
$(3.142 \times 0.2437) \times(3.142 \times 10.5) \times 4=101.04554$ sq in.

+ (plus)

$\mathrm{B}=$ Surface area of the tendons $=$ surface area of the tendons $(\mathrm{Pi} \times \mathrm{x} 0.5) \mathrm{x}$ $12 \mathrm{in} / \mathrm{ft} \times \mathrm{x}$ tendons.

$(3.142 \times 0.5) \times 12 \times 7=131.964$ sq in.

Surface area of reinforcing steel per ft of pile $=101.04554+131.964$

Surface area of reinforcing steel per $\mathrm{ft}$ of pile $=233.01 \mathrm{sq}$ in. $(1.62 \mathrm{sq} \mathrm{ft}$ )

Surface area of octagonal concrete pile per ft (nominal 8 in faces)

$=$ Surface Area of each face ( 8 in $\times 12$ in $) \times 8$ Faces

$=(8$ in $\times 12$ in $) \times 8$

Surface area of octagonal concrete pile per $\mathrm{ft}=\mathbf{7 6 8}$ sq in. $(5.3 \mathrm{sq} \mathbf{f t})$

For the submerged and mud line area the steel reinforcement is assumed to be 7 each $1 / 2$ in. diameter tendons consisting of 7 wire strands. The spiral tie is $3 \mathrm{GA}$. (0.2437 in. diam.) on a $6 \mathrm{in}$. pitch on a diameter of $10.5 \mathrm{in}$. To calculate the total surface area of the spiral tie we will assume that there are 2 circular (10.5 in. diameter) ties per foot of pile.

The total area per linear foot of pile is thus:

\section{Surface area of reinforcing steel per $\mathrm{ft}$ of pile $=\mathrm{A}+\mathrm{B}$}

$\mathrm{A}=$ Surface area of the spiral tie $=$ surface area of the $3 \mathrm{GA}$ (0.2437 in. dia.) wire (Pi x 0.2437) $x$ length of wire (Pi x 10.5) x 2 spirals/ $\mathrm{ft}$ of pile.

$(3.142 \times 0.2437) \times(3.142 \times 10.5) \times 2=50.522772 \mathrm{sq}$ in.

+ (plus) 
$\mathrm{B}=$ Surface area of the tendons $=$ surface area of the tendons $(\mathrm{Pi} \times 0.5) \mathrm{x}$ $12 \mathrm{in} / \mathrm{ft} \times \mathrm{x}$ tendons.

$$
(3.142 \times 0.5) \times 12 \times 7=131.964 \text { sq in. }
$$

Surface area of reinforcing steel per ft of pile $=50.522772+131.964$

Surface area of reinforcing steel per $\mathrm{ft}$ of pile $=\mathbf{1 8 2 . 4 8}$ sq in. $(\mathbf{1 . 2 7} \mathrm{sq} \mathbf{f t})$

$$
\begin{aligned}
& =\quad 182.46 \mathrm{sq} \text { in } . \\
& =\quad 1.27 \mathrm{sqft}
\end{aligned}
$$

Table A1. Surface area calculations.

\begin{tabular}{|l|l|l|l|l|}
\hline \multirow{2}{*}{ Zone } & Pile Length & \multicolumn{1}{|c|}{ Concrete Area } & \multicolumn{1}{c|}{ Steel Area } & \multirow{2}{*}{$\begin{array}{c}\text { Steel/Concrete } \\
\text { Ratio }\end{array}$} \\
\cline { 2 - 4 } & \multicolumn{1}{|c|}{$\mathrm{ft}$} & \multicolumn{1}{|c|}{ sq ft } & \multicolumn{1}{c|}{ sq ft } & \\
\hline Tidal \& splash & 8 & 42.40 & 12.96 & $0.31: 1$ \\
\hline Submerged \& Mud & 66 & 349.80 & 83.82 & $0.24: 1$ \\
\hline Totals & 74 & 392.20 & 96.78 & \\
\hline
\end{tabular}

\section{Anode weight calculations}

To ascertain life expectancy the weight of the anode is calculated and used in the monitoring system to calculate life expectancy. The following calculations provide the weight of zinc used in the cathodic protection design.

\section{For the tidal/splash zone:}

The Unit weight of the expanded zinc mesh $=1.60 \mathrm{lb} / \mathrm{sq} \mathrm{ft}$ min. as per the manufacturers data sheet.

Area covered by the anode $=$ Surface area of each strip (( 7 in. $\mathrm{x} 12$ in./ $\mathrm{ft} \times 8$ $\mathrm{ft}) / 144 \mathrm{sq}$ in $/ \mathrm{sq} \mathrm{ft})=4.67 \mathrm{sq} \mathrm{ft}$. Total mesh area $=8$ strips $\times 4.67 \mathrm{sf} / \mathrm{strip}=$ $37.36 \mathrm{sf}$.

Total anode weight in tidal/ splash zone $=$ total area of mesh (37.36 sf) $\mathrm{x}$ weight of zinc mesh $(1.60 \mathrm{lb} / \mathrm{sf})=59.78 \mathrm{lb}$.

Total anode weight in submerged/mud zone: $48 \mathrm{lb}$ (net) 
The anode configuration used for the project was 4 bulk zinc alloy anodes at $12 \mathrm{lb}$ each, specifically formulated for seawater applications. An anode was placed on every other face of the octagonal pile.

Table A2. Anode weight calculations.

\begin{tabular}{|l|l|l|l|}
\hline \multirow{2}{*}{ Zone } & Weight & Steel Area & Steel to Weight Ratio \\
\cline { 2 - 4 } & Ib & sq ft & lb per sq ft \\
\hline Tidal \& splash & 59.78 & 12.96 & 4.61 \\
\hline Submerged \& Mud & 48 & 83.82 & 0.57 \\
\hline Totals & 107.64 & 96.78 & \\
\hline
\end{tabular}

\section{Service life}

The service life of the cathodic protection system is determined by the amount of protective current delivered by the system. The following table provides an indication of the life expectancy from a variety of output current densities.

The calculation used to determine life is as follows:

$L=\left(\frac{w}{I x C r}\right) x U f$

$\mathrm{L}=$ Life in Years

$\mathrm{W}=$ Weight in $\mathrm{lb}$

I = Output Current in Amperes

$\mathrm{Cr}=$ Anode practical consumption rate equals the theoretical rate $\mathrm{x}$ efficiency factor

Uf =Anode Utilization Factor Typically 85\%1

\section{Electrochemical Properties of Zinc}

Current Capacity -

Current Efficiency
Theoretical 372 amp-hours/pound or $23.5 \mathrm{lb}$. per amp-yr

$90 \%$ in sea water

\footnotetext{
1 Uhligs Corrosion Handbook, $2^{\text {nd }}$ Edition.
} 
Current Capacity at 90\% efficiency

335 amp-hours/pound or $26 \mathrm{lb}$. per amp-yr

Potential in Sea Water

Surface area of anode mesh
-1.1 volts vs. Sat. Cu-CuSO4 Self Consumption 1.0 mils per year 1

The tables below indicate the life expectancy of both types of anode based on various steel current densities. A steel current density of $0.2 \mathrm{~mA} / \mathrm{sq} \mathrm{ft}$ is a conservative value after polarization and indicates life expectancies of 37 years and 109 years for the mesh and bulk anodes respectively.

Table A3. Life expectancy of the anode mesh in the tidal and splash zone.

\begin{tabular}{|c|c|c|c|c|c|c|}
\hline $\begin{array}{l}\text { Anode } \\
\text { Weight }\end{array}$ & $\begin{array}{c}\text { Steel } \\
\text { Current } \\
\text { Demand }\end{array}$ & $\begin{array}{l}\text { Anode } \\
\text { Current } \\
\text { Output } \\
\text { (Steel } \\
\text { Area x } \\
\text { Demand) }\end{array}$ & $\begin{array}{c}\text { Consumption } \\
\text { A= (Effective } \\
\text { Output/Anode } \\
\text { Output) } \\
\text { Hours per } \\
\text { year/A }\end{array}$ & $\begin{array}{c}\text { Self } \\
\text { Consumption } \\
\text { per year }\end{array}$ & $\begin{array}{c}\text { Total } \\
\text { Consumption } \\
\text { Per Year }\end{array}$ & $\begin{array}{c}\text { Life } \\
\text { Expectancy }\end{array}$ \\
\hline \multirow{5}{*}{$\begin{array}{l}59.78 \\
\mathrm{lb}\end{array}$} & mA/S.F. & $\mathrm{mA}$ & Lb/yr & $\mathrm{Lb} / \mathrm{yr}$ & $\mathrm{Lb}$ & Years \\
\hline & 0.1 & 1.296 & 0.0338 & 1.55 & 1.5838 & 37.74 \\
\hline & 0.2 & 2.592 & 0.0678 & 1.55 & 1.6178 & 36.95 \\
\hline & 0.5 & 6.48 & 0.1694 & 1.55 & 1.7194 & 34.76 \\
\hline & 1.0 & 12.96 & 0.3389 & 1.55 & 1.8889 & 31.64 \\
\hline
\end{tabular}

Table A4. Life expectancy of the bulk anode in the submerged zone.

\begin{tabular}{|l|l|l|l|l|}
\hline \multirow{2}{*}{$\begin{array}{l}\text { Anode } \\
\text { Weight }\end{array}$} & $\begin{array}{l}\text { Steel Current } \\
\text { Demand }\end{array}$ & $\begin{array}{l}\text { Anode Current } \\
\text { Output } \\
\text { (Steel Area x } \\
\text { Demand) }\end{array}$ & $\begin{array}{l}\text { Consumption } \\
\text { A= (Effective } \\
\text { Output/Anode } \\
\text { Output) } \\
\text { Hours per year/A }\end{array}$ & Life Expectancy \\
\hline \multirow{4}{*}{$48 \mathrm{lb}$} & mA/S.F. & $\mathrm{mA}$ & Lbs/yr & Years \\
\cline { 2 - 6 } & 0.1 & 8.382 & 0.219 & 219.17 \\
\cline { 2 - 6 } & 0.2 & 16.764 & 0.438 & 109.58 \\
\cline { 2 - 6 } & 0.5 & 41.91 & 1.095 & 43.83 \\
\cline { 2 - 6 } & 1.0 & 83.82 & 2.19 & 21.91 \\
\hline
\end{tabular}

\footnotetext{
1 Section 7.8.2 Zinc, subsections 7.8.2.2 Anode Efficiency and 7.8.2.3 Potentials (pg. 125) of Appendix A of UFC 3-570-02N, Electrical Engineering Cathodic Protection.
} 



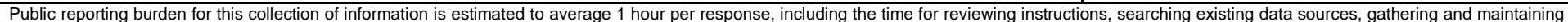

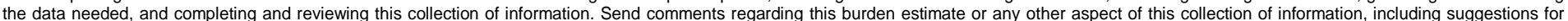

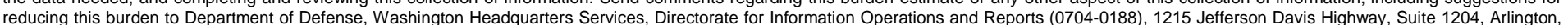

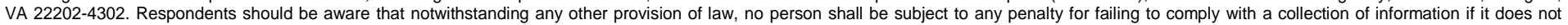
display a currently valid OMB control number. PLEASE DO NOT RETURN YOUR FORM TO THE ABOVE ADDRESS.
1. REPORT DATE (DD-MM-YYYY) 2. REPORT TYPE
June 2013$$
\text { Final }
$$

4. TITLE AND SUBTITLE

Polymer Composite Wrapping and Cathodic Protection System for Reinforced Concrete

Piles in Marine Applications

3. DATES COVERED (From - To)

5a. CONTRACT NUMBER

5b. GRANT NUMBER

5c. PROGRAM ELEMENT NUMBER

Corrosion Prevention and Control

6. AUTHOR(S)

David M. Bailey, Vincent F. Hock, P.A. Noyce, and M. Restly

5d. PROJECT NUMBER

F08-AR07

5e. TASK NUMBER

5f. WORK UNIT NUMBER

7. PERFORMING ORGANIZATION NAME(S) AND ADDRESS(ES)

US Army Engineer Research and Development Center

8. PERFORMING ORGANIZATION REPORT

NUMBER

ERDC/CERL TR-13-6

Construction Engineering Research Laboratory

P.O. Box 9005

Champaign, IL 61826-9005

9. SPONSORING I MONITORING AGENCY NAME(S) AND ADDRESS(ES)

Office of the Secretary of Defense (OUSD(AT\&L))

3090 Defense Pentagon

Washington, DC 20301-3090

10. SPONSOR/MONITOR'S ACRONYM(S)

OSD

11. SPONSOR/MONITOR'S REPORT NUMBER(S)

\section{DISTRIBUTION / AVAILABILITY STATEMENT}

Approved for public release; distribution is unlimited.

\section{SUPPLEMENTARY NOTES}

\section{ABSTRACT}

Military piers in marine environments are typically supported atop steel-reinforced concrete piles that are subject to corrosion and concrete deterioration. The failure of even one pile presents a risk of catastrophic structural failure and interruption of operations. Patching deteriorated concrete does not stop corrosion of the reinforcement and may even accelerate it. An impact and corrosion protection wrap (ICPW) system, incorporating a composite structural wrap and cathodic protection system, was designed to rehabilitate deteriorated steel-reinforced concrete marine piles in service at Kawaihae Harbor, HI. The purpose of the technology is to reduce pier life-cycle costs and downtime by inhibiting corrosion-related damage to steel-reinforced concrete piles.

The ICPW system consists of a composite reinforced polymeric wrap with an integrated galvanic anode to provide protection in the tidal splash zone. Corrosion activity in 20 rehabilitated piles on two piers was monitored using reference electrodes and data loggers. Results of the demonstration indicate that the system can protect and extend the life of in-service reinforced concrete structural piles in a corrosive marine environment. An economic analysis determined that full implementation of the system on all piles of the two demonstration piers would provide 3.16 return on investment.

\section{SUBJECT TERMS}

corrosion, reinforced concrete, composite structural reinforcement, cathodic protection, corrosive environments

\section{SECURITY CLASSIFICATION OF:}

\section{a. REPORT}

Unclassified

\section{b. ABSTRACT}

Unclassified c. THIS PAGE

Unclassified
17. LIMITATION OF ABSTRACT
18. NUMBER OF PAGES

63 19a. NAME OF RESPONSIBLE PERSON

19b. TELEPHONE NUMBER (include area code) 